Review

\title{
Nanoparticle-Mediated Systemic Delivery of siRNA for Treatment of Cancers and Viral Infections
}

\author{
Mohamed Shehata Draz ${ }^{1,2^{*}}$, Binbin Amanda Fang $3,4,{ }^{*}$, Pengfei Zhang5, Zhi Hu${ }^{6}$, Shenda Gu6 ${ }^{6}$ Kevin C. \\ Weng4, Joe W. Gray4,6, Fanqing Frank Chen 1,3,4凶 \\ 1. Zhejiang-California International Nanosystems Institute, Zhejiang University, Hangzhou, Zhejiang 310029, China \\ 2. Faculty of Science, Tanta University, Tanta 31527, Egypt \\ 3. Life Sciences College, Fudan University, Shanghai 200433, China \\ 4. Life Sciences Division, Lawrence Berkeley National Laboratory, Berkeley, CA 94127, USA \\ 5. Translational Medicine Center, Changzheng Hospital, The Second Military Medical University, 800 Xiangyin Road, Shanghai 200433, P.R. China. \\ 6. Biomedical Engineering, OHSU Center for Spatial Systems Biomedicine, Oregon Health and Science University, Portland, OR 97239, USA \\ * These two authors contributed equally. \\ $\square$ Corresponding author: Fanqing Frank Chen, f_chen@lbl.gov or frank_chen@fudan.edu.cn.
}

(C) Ivyspring International Publisher. This is an open-access article distributed under the terms of the Creative Commons License (http://creativecommons.org/ licenses/by-nc-nd/3.0/). Reproduction is permitted for personal, noncommercial use, provided that the article is in whole, unmodified, and properly cited.

Received: 2014.04.15; Accepted: 2014.05.27; Published: 2014.06.II

\begin{abstract}
RNA interference (RNAi) is an endogenous post-transcriptional gene regulatory mechanism, where non-coding, double-stranded RNA molecules interfere with the expression of certain genes in order to silence it. Since its discovery, this phenomenon has evolved as powerful technology to diagnose and treat diseases at cellular and molecular levels. With a lot of attention, short interfering RNA (siRNA) therapeutics has brought a great hope for treatment of various undruggable diseases, including genetic diseases, cancer, and resistant viral infections. However, the challenge of their systemic delivery and on how they are integrated to exhibit the desired properties and functions remains a key bottleneck for realizing its full potential. Nanoparticles are currently well known to exhibit a number of unique properties that could be strategically tailored into new advanced siRNA delivery systems. This review summarizes the various nanoparticulate systems developed so far in the literature for systemic delivery of siRNA, which include silica and silicon-based nanoparticles, metal and metal oxides nanoparticles, carbon nanotubes, graphene, dendrimers, polymers, cyclodextrins, lipids, hydrogels, and semiconductor nanocrystals. Challenges and barriers to the delivery of siRNA and the role of different nanoparticles to surmount these challenges are also included in the review.
\end{abstract}

Key words: Small interfering RNA; Nanoparticle; RNA interference; Delivery; Cancer; Virus.

\section{Introduction}

In 1998, Fire and Mello et al. discovered that potent and specific RNA interference can be induced by double-stranded RNA (dsRNA) in Caenorhabditis elegans [1]. Further investigations confirmed that similar dsRNA-triggered phenomena also exist in many other species such as plants [2], Drosophila [3], and mammalian cells $[4,5]$. The past decade has witnessed an explosion of research on small regulatory RNAs that has yielded a basic understanding of many types of small RNAs in diverse eukaryotic species and the functions of key protein factors amidst the RNA silencing pathways. RNA silencing is recognized as a widespread mechanism of gene regulation in eukaryotes. The key machinery of RNAi pathway is that dsRNA molecules, experimentally or naturally occurring, can be recognized and cleaved into 21-23 nucleotide duplex termed small interfering RNA by Dicer homologues that have dsRNA binding domain and sRNaseIII-like enzyme activity, see Figure $1[6,7]$. The siRNAs are incorporated into the multi-subunit ef- 
fector complex called RNA-induced silencing complex (RISC), therefore activate the helicase activity leading to cleavage of the sense strand of siRNA $[8,9]$. The remaining antisense strand recognizes the homologue region with base-pairing and degrading the target messenger RNA (mRNA) mediated by the Argonaute (Ago) family proteins with endonuclease activity, which is the catalytic core of active RISC, resulting in inhibition of gene expression [10-12]. RNAi technology has become a routine laboratory research tool for gene functional study and is making its way as a revolutionary class of therapeutics for treatment of cancers and different viral infections. This paper is focused primarily on synthetic siRNA and its delivery using nanoparticulate systems.

\section{RNAi: a potential revolutionary thera- peutics}

The discovery of RNAi raises the possibility to explore new approaches for many incurable and difficult to treat diseases. The advantage of siRNA as therapeutics is that siRNA can target many undruggable genes. Other than antibody-based therapeutics that mainly targets receptors present on the cell sur-

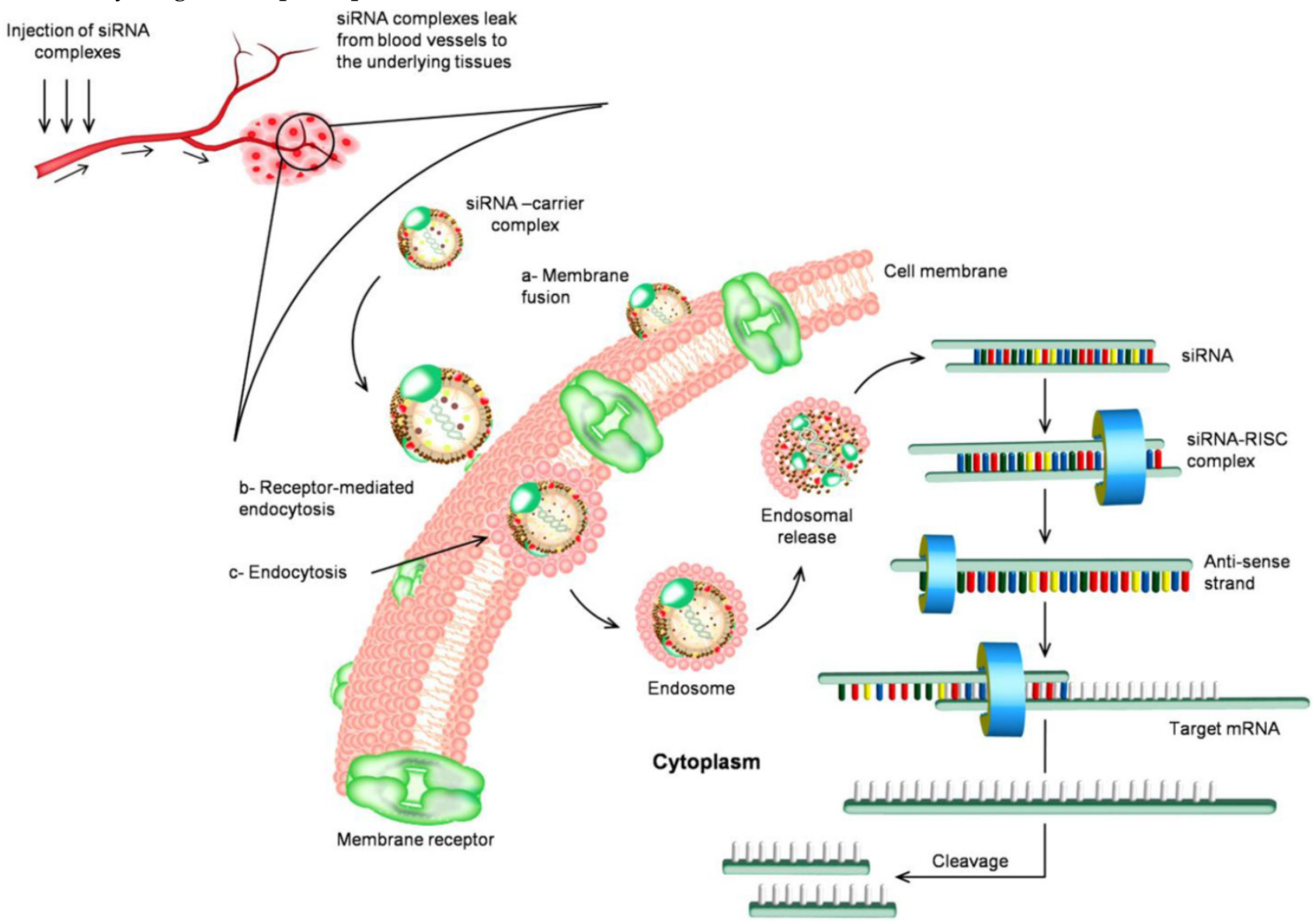

Figure I. The circulation routine of siRNA and the biological mechanism of RNAi in vivo. siRNA is associated with nanoparticles either through chemical linkage via covalent bonds or through non-covalent interactions. Nanoparticles facilitate cellular uptake of siRNA cargo the process that commonly occurs through three main pathways (a) membrane fusion, (b) receptor-mediated endocytosis, and (c) direct endocytosis. The mechanism of internalized siRNA is controlled and initiated by the interaction with RNA-induced silencing complex (RISC). The remaining antisense strand recognizes the homologue region with base-pairing and degrading the target mRNA resulting in inhibition of gene expression. face, only a very small number of targets, mostly kinases, have been validated for traditional small molecule drugs. In addition, it is found that diseases such as cancer, genes are often deregulated by high-level amplifications [13-15]. Such genes are particularly interesting as therapeutic targets for treatment of patients that are refractory to existing therapies. However, only very few of these genes, including FGFR1, IKBKB, ERBB2, etc., are considered druggable [13]. Some malignant diseases are known to be caused by multiple gene mutations, copy number change or epigenetic changes $[16,17]$. Studies show that cancers are highly heterogeneous, resulting in each patient being "unique" and requiring personalized treatment. Furthermore, cancers initially sensitive to conventional chemotherapeutics often adapt tolerance to targeted therapy by gene mutations and other mechanisms [18]. A siRNA-based drug may target any mRNAs of interest, regardless of their cellular locations or structures of the translated proteins. Therefore, siRNA therapeutics shows promises to meet these challenges and has emerged as new generation bio-drugs under intensive investigation. 
Significant progress has been made for the development of siRNA based drugs since the discovery of RNAi machinery. Currently, several potential siRNA candidates are undergoing clinical trials summarized in Table 1, such as Bevasiranib, the first siRNA based drug in clinical trials, which targets vascular endothelial growth factor (VEGF) pathway for treatment of macular degeneration; ALN-RSV01 to treat virus respiratory diseases, and CALAA-01 to silence ribonucleotide reductase subunit 2 (RRM2) gene, which is highly overexpressed in advanced cancers. Lipid-based carriers of siRNA therapeutics can target the liver in metabolic diseases and are being assessed in clinical trials for treatment of hypercholesterolemia [19]. Phase $\mathrm{Ib}$ clinical trial of the first-in-human mutation-targeted siRNA Td101 against an inherited skin disorder is now completed.

Table I. List of siRNA-based drugs targeting different diseases were in clinical trials.

\begin{tabular}{|c|c|c|c|c|c|}
\hline Disease & Target & Vehicle & Drug Name & Company & Status \\
\hline \multicolumn{6}{|l|}{ Cancers } \\
\hline Solid tumor & RRM2 & $\begin{array}{l}\text { Cyclodextrin, } \\
\text { Transferrin, PEG }\end{array}$ & CALAA-01 & Calando Pharmaceuticals & $\begin{array}{l}\text { Terminated, } \\
\text { Phase I }\end{array}$ \\
\hline Advanced solid tumors & PKN3 & Liposomes & Atu027 & Silence Therapeutics AG & $\begin{array}{l}\text { Completed, } \\
\text { Phase I }\end{array}$ \\
\hline $\begin{array}{l}\text { Pancreatic ductal } \\
\text { adenocarcinoma }\end{array}$ & Mutated KRAS oncogene & LODER polymer & siG12D LODER & Silenseed Ltd & $\begin{array}{l}\text { Active, } \\
\text { Phase I }\end{array}$ \\
\hline $\begin{array}{l}\text { Metastatic melanoma } \\
\text { absence of CNS metastases }\end{array}$ & LMP2, LMP7, and MECL1 & Transfection & NCT00672542 & Duke University & $\begin{array}{l}\text { Completed, } \\
\text { Phase I }\end{array}$ \\
\hline Chronic myeloid leukemia & Fusion genes & SV40 & $\begin{array}{l}\text { SV40 vectors- carrying } \\
\text { siRNA }\end{array}$ & $\begin{array}{l}\text { Hadassah Medical Organiza- } \\
\text { tion }\end{array}$ & $?$ \\
\hline \multicolumn{6}{|l|}{ Virus infections } \\
\hline RSV & RSV nucleocapsid & Naked siRNA & ALN-RSV01 & Alnylam Pharmaceuticals & $\begin{array}{l}\text { Completed, } \\
\text { Phase II }\end{array}$ \\
\hline \multirow[t]{2}{*}{ HBV } & $\begin{array}{l}\text { Pre gen./Pre-C, Pre-S1, } \\
\text { Pre-S2/S, X }\end{array}$ & Plasmid DNA & NUC B1000 & Nucleonics & $\begin{array}{l}\text { Completed, } \\
\text { Phase I }\end{array}$ \\
\hline & HBV conserved sequences & $\mathrm{DPC}$ & ARC-520 & $\begin{array}{l}\text { Arrowhead Research } \\
\text { Corporation }\end{array}$ & $\begin{array}{l}\text { Recruiting, } \\
\text { Phase II }\end{array}$ \\
\hline HIV & $\begin{array}{l}\text { HIV Tat protein, HIV TAR } \\
\text { RNA, human CCR5 }\end{array}$ & Lentivirus & $\begin{array}{l}\text { pHIV7-shI-TARCCR5R } \\
\text { Z }\end{array}$ & $\begin{array}{l}\text { City of Hope Medical } \\
\text { Center/Benitec }\end{array}$ & $\begin{array}{l}\text { Terminated, } \\
\text { Phase } 0\end{array}$ \\
\hline $\mathrm{HCV}$ & miR-122 & Naked LNA & SPC3649 (LNA) & Santaris Pharm & $\begin{array}{l}\text { Completed, } \\
\text { Phase II }\end{array}$ \\
\hline EBOV & $\begin{array}{l}\text { EBOV polymerase L, VP24, } \\
\text { and VP35 regions }\end{array}$ & SNALP & TKM-100201 & $\begin{array}{l}\text { Tekmira Pharmaceuticals } \\
\text { Corporation }\end{array}$ & $\begin{array}{l}\text { Terminated, } \\
\text { Phase I }\end{array}$ \\
\hline \multicolumn{6}{|l|}{ Other diseases } \\
\hline Hypercholesterolemia & APOB & SNALP & PRO-040201 & $\begin{array}{l}\text { Tekmira Pharmaceuticals } \\
\text { Corporation }\end{array}$ & $\begin{array}{l}\text { Terminated, } \\
\text { Phase I }\end{array}$ \\
\hline Pachyonychia Congenita & keratin K6a & Naked siRNA & TD101 & TransDerm, Inc & $\begin{array}{l}\text { Completed, } \\
\text { Phase I }\end{array}$ \\
\hline $\begin{array}{l}\text { Delayed graft function } \\
\text { kidney transplant }\end{array}$ & P53 & Naked siRNA & I5NP & Quark Pharmaceuticals & $\begin{array}{l}\text { Active, Phase } \\
\text { I/II }\end{array}$ \\
\hline Acute renal failure & P53 & Naked siRNA & $\mathrm{I} 5 \mathrm{NP}$ & Quark Pharmaceuticals & $\begin{array}{l}\text { Terminated, } \\
\text { Phase I }\end{array}$ \\
\hline $\begin{array}{l}\text { Glaucoma; } \\
\text { ocular hypertension }\end{array}$ & ADRB2 & Naked siRNA & SYL040012 & Sylentis, S.A. & $\begin{array}{l}\text { Completed, } \\
\text { Phase I/II }\end{array}$ \\
\hline Dry eye syndrome & TRPV1 & Naked siRNA & SYL1001 & Sylentis, S.A. & $\begin{array}{l}\text { Recruiting, } \\
\text { Phase II }\end{array}$ \\
\hline Wet AMD & VEGF & Naked siRNA & Bevasiranib & Opko Health, Inc. & $\begin{array}{l}\text { Terminated, } \\
\text { Phase III }\end{array}$ \\
\hline Diabetic AMD & VEGF & Naked siRNA & Bevasiranib & Opko Health, Inc. & $\begin{array}{l}\text { Completed, } \\
\text { Phase II }\end{array}$ \\
\hline Chronic optic nerve atrophy & Caspase-2 & Naked siRNA & QPI-1007 & Quark Pharmaceuticals & $\begin{array}{l}\text { Completed, } \\
\text { Phase I }\end{array}$ \\
\hline AMD; CNV & VEGFR & Naked siRNA & Sirna-027/AGN211745 & $\begin{array}{l}\text { Allergan \& Sirna Therapeutics } \\
\text { Inc. }\end{array}$ & $\begin{array}{l}\text { Completed, } \\
\text { Phase II }\end{array}$ \\
\hline AMD/DME & RTP801 & Naked siRNA & PF-655 & $\begin{array}{l}\text { Quark Pharmaceuticals \& } \\
\text { Pfizer }\end{array}$ & $\begin{array}{l}\text { Completed, } \\
\text { Phase II }\end{array}$ \\
\hline
\end{tabular}

Resource: http://clinicaltrials.gov.

CNS, central nervous system; RSV, respiratory syncytial virus; HBV, hepatitis B virus; HIV, human immunodeficiency virus; HCV, hepatitis C virus; EBOV, Ebola virus; AMD, Age-Related Macular Degeneration; CNV, choroidal neovascularization; RRM2, Ribonucleotide reductase subunit 2; PKN3, protein kinase n3; KRAS oncogene,

Kirsten rat sarcoma viral oncogene; LMP2, large multifunctional peptidase 2; LMP7, large multifunctional peptidase 7; MECL1, multicatalytic endopeptidase complex-like-1; HIV Tat protein, HIV-1-trans-activating protein; HIV TAR, HIV trans-activation response; CCR5, human CC chemokine receptor 5; VP24, virus protein 24; VP35, virus protein 35; APOB, apolipoprotein B; ADRB2, beta-2 adrenergic receptor; TRPV1, transient receptor potential vanilloid 1; VEGF(R), Vascular endothelial growth factor (receptor); cysteine-aspartic proteases-2 (Caspase-2); PEG, polyethylene glycol; SV40,9 Simian virus 40; DPC, dynamic polyconjugate; SNALP, stable nucleic acid-lipid particle. 


\section{Challenges and barriers to the systemic delivery of siRNA}

As a therapeutic strategy, RNAi offers several advantages over small-molecule drugs, as virtually all genes are susceptible to targeting by siRNA molecules. This advantage is, however, compromised by the challenges of safe and effective delivery of oligonucleotides to diseased tissues in vivo, summarized in Table 2. On the top of these challenges is the targeting specificity and stability of the administrated siRNA. Any inadvertent silencing of nontargeted genes "off-target effect" may lead to problems in interpretation of data and potential toxicity. The design and selection of potent siRNAs should be carefully performed. The basic parameters for choosing siRNAs involve consideration of internal repeated sequences, secondary structure, GC content, base preference at specific positions in the sense strand, and appropriate siRNA length (19-22 bps). 2'-O-methyl ribosyl group substitution at position 2 in the guide strand could reduce silencing of most off-target transcripts with complementarity to the siRNA guide [20,21]. In addition, the stability remains major challenge to application of siRNA in vivo. The naked siRNAs face rapid degradation in the extracellular environment and are not efficiently internalized into cells. The RNA backbone contains ribose, which has a hydroxyl group in the 2' position of the pentose ring instead of a hydrogen atom [22], which makes the RNA backbone very susceptible to hydrolysis by serum nucleases that cleave along the phosphodiester backbone of nucleic acids. Chemical modifications of siRNA on the sugar-phosphate backbone such as 2'-fluoro and 4'-thio modifications, incorporation of locked nucleic acids, phosphorothioation, methyl phosphonation can increase stability of dsRNA under serum-containing conditions [23]. The use of siRNA delivery vehicles is also essential for practical siRNA-mediated silencing. The proper delivery vehicles would provide protection to siRNA from degradation in the serum during circulation. On the other hand, there are multiple mechanisms by which siRNA may be recognized by receptors of the innate immune system, including both endosomal Toll-like receptors and cytoplasmic receptors [24] that can lead to systemic inflammation in vivo through inducing the production of type I interferons and inflammatory cytokines. This challenge of RNA-induced immunostimulation may be reduced by proper siRNA design considerations, including choices of siRNA target sequence, chemical modifications to the RNA backbone, and the delivery formulation and method. So far, two cytoplasmic receptors that have long been known to recognize long dsRNA are protein kinase $R$ [25] and 2'-5'-oligoadenylate synthetase [24]. A variety of siRNA backbone modification chemistries have been investigated for their capacity to suppress immune activation while maintaining gene silencing activity. Making substitutions at uridine residues with 2'-fluoro, 2'-deoxy or 2'-O-methyl groups often reduces the immunostimulatory capacity of siRNA [26, 27]. The termini (ends) of a siRNA are major determinants of immune recognition. siRNA with added 3' overhangs such as UU, can reduce immune recognition and induce more efficiently gene silencing in vivo [28].

Table 2. Challenges and barriers to the systemic delivery of siRNA.

\begin{tabular}{ll}
\hline Challenge & Solution/approach \\
\hline Specificity & Well design, optimize algorism \\
Stability/degradation & Chemical modification, carrier \\
Immune response & Chemical modification \\
Clearance by RES systems & Encapsulation \\
Targeting/biodistribution & Receptor mediated \\
Endosomal escaping & pH responsive release \\
Dissociation from carrier & Cleavable polymers for siRNA \\
Toxicity & Reduce off-target effect, biocompat- \\
& ible and biodegradable carrier
\end{tabular}

RES: reticuloendothelial system.

The systemic delivery of siRNA is further hampered by many additional anatomical and physiological defensive barriers presented by the human body, and siRNA need to overcome before to reach its site of action. The first barrier includes the renal clearance through kidney or the entrapment in reticuloendothelial system (RES) that exists in the liver, spleen, lung and bone marrow. Many delivery systems larger than $\sim 20 \mathrm{~nm}$ and less than $\sim 100 \mathrm{~nm}$ in diameter are thought to be optimal for avoiding both renal and RES clearance and favorably improve the passive intra-tumoral delivery due to the unique features of leaky vasculature with capillary pore size of $100-800$ $\mathrm{nm}$ and the absence of lymphatic drainage [29, 30]. Surface modifications using hydrophilic and flexible polyethylene glycol and other surfactant copolymers, e.g., poloxamers, polyethylene oxide, are also suggested to prepare stealth delivery carriers that can remain in the systemic circulation for a prolonged period of time [31, 32]. The second barrier is the endothelial lining and extracellular matrix barrier. For successful delivery, siRNA and its carriers must be readily to extravasate and move through the complex extracellular matrix to reach the diseased cells. The normal endothelial layer lining most of tissues allows the permeation of materials through abundant small pores of about 45 angstroms diameter and relatively scarce large pores of about 250 angstroms. This small pore system restricts the permeation of materials 
larger than 4 or 5 nanometers [33, 34]. Only naked siRNA oligonucleotides or that are modified with molecular conjugates should be readily permeable, while other types of formulations may not be able to efficiently reach the underlying tissues. However, this represents an opportunity for nanocarriers to specifically deliver siRNA to certain types of tumors that have fenestrated endothelia. The third barrier is biodistribution, and it can be conquered by several approchaces particularly via targeted delivery of siRNA [35-37]. After siRNA is successfully delivered into the cells, how it can be efficiently released from endosome also presents a big challenge. If siRNA remains inside the endosome for too long, it will inevitably be degraded. Several methods aiming to enhance endosomal escape include conjugation with lipids or peptides, $\mathrm{pH}$-sensitive lipoplexes, etc [38]. Figure 1 presents the circulation routine of siRNA complexes and the biological mechanism of RNAi in vivo.

\section{Nanoparticles in RNAi therapeutics}

Nanoparticulate systems have emerged in last few years as an alternative material for advanced diagnostic and therapeutic applications in medicine. Compared to molecular medicine, nanoparticles offer many advantages that overcome a range of challenges and barriers summarized in the previous section, particularly, bioavailability and biodistribution of therapeutic agents. The first remarkable property of nanoparticles is their superior in vivo retention by decreasing enzymatic degradation and sequestration by phagocytes of the reticulo-endothelial systems. This is mostly attributed to their immunochemically inert surfaces in contact with the biological environment. Increased deposition to the diseased sites via compromised vasculatures in the phenomenon called enhanced permeability and retention effect also contributes to their improved deposit to diseased sites and efficacy [37]. Various other properties of nanoparticles, including size, shape, surface charge, density, composition, and surface chemistry have been investigated [39]. The accumulated data presents interesting correlations among all these properties that led to a range of outcomes. Research has been focused on windows of optimal and controllable properties that guides the design and synthesis of nanoparticle formulations [40].

The properties that have been validated in chemotherapeutics are also exploited for siRNA packaging and delivery [41-46]. The effort began with stable association of siRNA molecules with the nanoparticles and their retention in circulation. Methods of conjugating siRNAs with other inert and biocompatible molecules, such as cholesterol and long-chain fatty acids have been reported [47, 48]. Complexation, encapsulation, and non-covalent association of siRNA into several nanoconstructs are reported. Success has been limited to date and there are still numerous challenges associated with many stages along the delivery process especially several recent reports on the toxicity and instability of some siRNA-nanoparticle complexes in vivo [49-51]. Different nanoparticle systems offer various advantages and disadvantages based on their composition, physical, and chemical characteristics, thus leading to a range of effectiveness when associated with siRNA. It has been found that unique challenges are associated with siRNA as many relatively successful technologies for oligonucleotides and DNA delivery did not translate to expected results for siRNA. An example is cationic lipid-gene complexes that are widely adapted for transfection and yet the release of siRNA during the intracellular pathways remains a major hurdle. Here we reviewed the main types of nanoparticle systems, and discuss their advantages, disadvantages, and the current state of development, summarized in Table 3 and Table 4.

Table 3. Types of nanoparticle systems used in siRNA delivery.

\begin{tabular}{|c|c|c|c|c|c|c|c|}
\hline \multicolumn{4}{|c|}{ Nanoparticle systema } & \multirow[t]{2}{*}{ Target gene ${ }^{b}$} & \multirow{2}{*}{$\begin{array}{l}\text { Silencing } \\
(\%)^{c}\end{array}$} & \multirow[t]{2}{*}{ Delivery routed } & \multirow[t]{2}{*}{ Ref } \\
\hline Type & Shape & Size & $\zeta$ potential & & & & \\
\hline \multicolumn{8}{|c|}{ Silica, silicon-based nanoparticles } \\
\hline \multirow[t]{4}{*}{ MSNPs } & Spherical & $\sim 220 \mathrm{~nm}$ & ND & Bcl-2 & $\sim 80 \%$ & In vitro, $\mathrm{A} 2780 / \mathrm{AD}$ cells & [54] \\
\hline & Spherical & $>130 \mathrm{~nm}$ & $29-38 \mathrm{mV}$ & GFP & $55-60 \%$ & In vitro, HEPA- 1 cells & [55] \\
\hline & Spherical & $832 \mathrm{~nm}$ & $25.4 \mathrm{mV}$ & Pgp & 80 or $90 \%$ & In vitro, $\mathrm{KBV} 1$ cells & [56] \\
\hline & Spherical & $>50 \mathrm{~nm}$ & ND & & $>50 \%$ & In vivo, i.v. injection in mice with MCF-7 cells & [57] \\
\hline \multicolumn{8}{|c|}{ Metal, metal oxides nanoparticles } \\
\hline \multirow[t]{6}{*}{ MNPs } & $\begin{array}{l}\text { Irregular/ } \\
\text { spherical }\end{array}$ & $\leq 156.2 \mathrm{~nm}$ & $26-46 \mathrm{mV}$ & GFP & $54.8 \%$ & In vitro, PC -3 cells & [64] \\
\hline & Spherical & $70-150 \mathrm{~nm}$ & $2 \pm 2 \mathrm{mV}$ & GFP & $21.5 \%$ & In vitro, SHEP cells & [65] \\
\hline & Spherical & $\sim 60 \mathrm{~nm}$ & $-2.6 \mathrm{mV}$ & GFP & $49.2 \%$ & In vitro, C6 glioma cells & [66] \\
\hline & Spherical & $75 \mathrm{~nm}$ & $-30 \mathrm{mV}$ & GFP & $20 \%$ & In vitro, MDA-MB- 435 and A549 cells & [67] \\
\hline & $\begin{array}{l}\text { Irregular/ } \\
\text { spherical }\end{array}$ & $100 \mathrm{~nm}$ & $-2-40 \mathrm{mV}$ & Luc & $30 \%$ & $\begin{array}{l}\text { In vitro, } 4 \mathrm{~T} 1 \text { cells } \\
\text { In vivo, i.t. injection in mice }\end{array}$ & [68] \\
\hline & $\begin{array}{l}\text { Irregular/ } \\
\text { spherical }\end{array}$ & $120 \mathrm{~nm}$ & $\sim 40 \mathrm{mV}$ & Luc & $\sim 75 \%$ & In vitro, $4 \mathrm{~T} 1$ cells & [70] \\
\hline AuNPs & Spherical & $100 \mathrm{~nm}$ & ND & GFP & 73.5 & In vitro, PC- 3 cells & [75] \\
\hline
\end{tabular}




\begin{tabular}{|c|c|c|c|c|c|c|c|}
\hline \multicolumn{4}{|c|}{ Nanoparticle systema } & \multirow[t]{2}{*}{ Target gene ${ }^{b}$} & \multirow{2}{*}{$\begin{array}{l}\text { Silencing } \\
(\%)^{c}\end{array}$} & \multirow[t]{2}{*}{ Delivery routed } & \multirow[t]{2}{*}{ Ref } \\
\hline Type & Shape & Size & $\zeta$ potential & & & & \\
\hline & Spherical & $26.8 \mathrm{~nm}$ & ND & EGFP & $72 \%$ & In vitro, K1 Cells & [77] \\
\hline & Spherical & $\sim 110 \mathrm{~nm}$ & $30 \pm 9 \mathrm{mV}$ & $\beta$-gal & $48 \%$ & In vitro, SVR-bag4 cells & [79] \\
\hline & Spherical & $18.2 \mathrm{~nm}$ & $\sim 12 \mathrm{mV}$ & GFP & $57.8 \%$ & In vitro, MDA-MB- 435 cells & [80] \\
\hline & Rod & $\begin{array}{l}\mathrm{L}=46.5 \mathrm{~nm} \\
\mathrm{D}=17.3 \mathrm{~nm}\end{array}$ & ND & Galectin-1 & $\sim 83 \%$ & In vitro, MDM cells & [81] \\
\hline \multicolumn{8}{|c|}{ Carbon-based materials } \\
\hline \multirow[t]{7}{*}{ CNTs } & SWNTs & $\begin{array}{l}\mathrm{D}=\sim 1-3 \mathrm{~nm} ; \\
\mathrm{L}=\sim 200 \mathrm{~nm}\end{array}$ & ND & $\begin{array}{l}\text { CXCR4 } \\
\text { /CD4 }\end{array}$ & $50-60 \%$ & In vitro, human $\mathrm{T}$ cells and PBMCs & [91] \\
\hline & SWNT & ND & ND & TERT & $>80 \%$ & In vitro, HeLa cells & [92] \\
\hline & SWNTs & $\mathrm{L}=50-300 \mathrm{~nm}$ & ND & Lamin A/C & $>40 \%$ & In vitro, HeLa cells & [93] \\
\hline & SWNTs & $\begin{array}{l}\mathrm{D}=1-1.4 \mathrm{~nm} \\
\mathrm{~L}=0.1-1 \mu \mathrm{m}\end{array}$ & ND & ERK & $75 \%$ & In vitro, cardiomyocytes & [94] \\
\hline & SWNT & $\mathrm{L}=50-300 \mathrm{~nm}$ & ND & cyclin A2 & $31 \%$ & In vitro, $\mathrm{K} 562$ cells & [95] \\
\hline & MWNT & $\begin{array}{l}\mathrm{D}=20-30 \mathrm{~nm} \\
\mathrm{~L}=0.5-2 \mu \mathrm{m}\end{array}$ & ND & siTOX & $50 \%$ & $\begin{array}{l}\text { In vitro, A549 cells } \\
\text { In vivo, i.t. injection in mice with Calu } 6 \text { cells }\end{array}$ & [96] \\
\hline & MWNT & $\begin{array}{l}\mathrm{D}=9.5 \mathrm{~nm} \\
\mathrm{~L}=1 \mu \mathrm{m}\end{array}$ & $-64 \mathrm{mV}$ & Luc & $60-90 \%$ & In vitro, $\mathrm{H} 1299$ cells & [209] \\
\hline $\begin{array}{l}\text { Graphene } \\
\text { Dendrimers }\end{array}$ & Sheet-like & $\sim 200 \mathrm{~nm}$ & $55.5 \mathrm{mV}$ & Bcl-2 & $30-60 \%$ & In vitro, HeLa cells & [106] \\
\hline \multirow[t]{3}{*}{ PAMAM } & Spherical & $72-165 \mathrm{~nm}$ & ND & siGLORed & ND & In vitro, A2780 cells & [112] \\
\hline & Spherical & $\sim 150 \mathrm{~nm}$ & ND & Bcl2 & $22-84 \%$ & In vitro, A2780 cells & {$[113,114]$} \\
\hline & Spherical & $120-180 \mathrm{~nm}$ & ND & Bcl2 & $70-50 \%$ & & \\
\hline \multicolumn{8}{|l|}{ Polymers } \\
\hline \multirow[t]{4}{*}{ Chitosan } & Spherical & $200 \mathrm{~nm}$ & ND & $\begin{array}{l}\text { POSTN, FAK, } \\
\text { PLXDC1 }\end{array}$ & $>51 \%$ & $\begin{array}{l}\text { In vitro, SKOV3ip1, HeyA8, A2780, A2780ip2 } \\
\text { and MOEC cells } \\
\text { In vivo, i.v injection in mice }\end{array}$ & [123] \\
\hline & ND & ND & ND & Src/Fgr & $81.8 \%$ & $\begin{array}{l}\text { In vitro, SKOV3ip1 and HeyA8 cells } \\
\text { In vivo, i.v. injection in mice }\end{array}$ & [124] \\
\hline & ND & $<500 \mathrm{~nm}$ & $51 \mathrm{mV}$ & HPV16 E7 & $\sim 31 \%$ & In vitro, CaSki cells & [125] \\
\hline & Spherical & $400-500 \mathrm{~nm}$ & $32-45 \mathrm{mV}$ & HPV16 E6 & $\sim 58 \%$ & In vitro, SiHa cells & [126] \\
\hline Dextran & Spherical & $100-300 \mathrm{~nm}$ & $-15.9 \mathrm{mV}$ & Luc & $60 \%$ & In vitro, PC-3 cells & [148] \\
\hline \multirow[t]{7}{*}{ Polycations } & ND & $7-40 \mathrm{~nm}$ & ND & Luc & Up to $90 \%$ & In vitro, Neuro 2A cells & [136] \\
\hline & & & & $\begin{array}{l}\text { VEGF } \\
\text { GFP }\end{array}$ & $\begin{array}{l}\sim 66 \% \\
\sim 80 \%\end{array}$ & In vitro, HepG2 cells & [143] \\
\hline & Spherical & $100-300 \mathrm{~nm}$ & $1.54 \mathrm{mV}$ & RFP & $80 \%$ & In vitro, B16F10 cells & [144] \\
\hline & ND & $100 \mathrm{~nm}$ & ND & GFP & $76 \pm 14 \%$ & In vitro, primary human glioblastoma cells & [145] \\
\hline & ND & $200 \mathrm{~nm}$ & $-2.7 \mathrm{mV}$ & VEGF & ND & In vitro, $\mathrm{PC}-3, \mathrm{~KB}, \mathrm{HeLa}, \mathrm{A} 2780$, and A549 cells & {$[146]$} \\
\hline & Spherical & $314 \pm 15 \mathrm{~nm}$ & $-6.0 \mathrm{mV}$ & RFP & ND & In vitro, B16F10 cells & {$[147]$} \\
\hline & ND & $1-5 \mu \mathrm{M}$ & ND & VEGF & $60 \%$ & In vitro, A2780 cells & [149] \\
\hline \multirow[t]{2}{*}{ Micelles } & ND & $75-85 \mathrm{~nm}$ & $>3.3 \mathrm{mV}$ & PLK-1 & ND & In vitro, OSRC-2 cells & [49] \\
\hline & Star-shaped & $56 \pm 3 \mathrm{~nm}$ & ND & EGFP & $74 \pm 1.5 \%$ & $\begin{array}{l}\text { In vitro, HeLa cells } \\
\text { In vivo, i.v. injection in mice }\end{array}$ & [138] \\
\hline \multicolumn{8}{|l|}{ Cyclodextrin } \\
\hline & ND & $\sim 70 \mathrm{~nm}$ & ND & RRM2 & $77 \%$ & $\begin{array}{l}\text { In clinical trial, i.v. injection, advanced solid } \\
\text { tumors }\end{array}$ & [153] \\
\hline & ND & $\sim 60-100 \mathrm{~nm}$ & $5-10 \mathrm{mV}$ & RRM2 & $50 \%$ & In vitro, Neuro2A-Luc cells & [155] \\
\hline & ND & $\sim 70 \mathrm{~nm}$ & ND & RRM2 & ND & In vivo, i.v. injection in monkeys & [157] \\
\hline & ND & $\sim 80 \mathrm{~nm}$ & $10 \mathrm{mV}$ & Luc & $50 \%$ & In vitro, In vivo, Neuro2A-Luc cells & [158] \\
\hline \multicolumn{8}{|c|}{ Lipid-based nanoparticles } \\
\hline \multirow[t]{8}{*}{ Liposomes } & Spherical & $184 \mathrm{~nm}$ & $42.9 \mathrm{mV}$ & siTOX & $50 \%$ & $\begin{array}{l}\text { In vitro, A549 cells } \\
\text { In vivo, i.t. injection in mice with Calu } 6 \text { cells }\end{array}$ & [96] \\
\hline & Spherical & $190 \mathrm{~nm}$ & $37.8 \mathrm{mV}$ & $\begin{array}{l}\text { Luc/ } \\
\text { GFP }\end{array}$ & $70 \%$ & $\begin{array}{l}\text { In vitro, } \mathrm{HT} 1080 \text { cells } \\
\text { In vivo, i.v. injection in mice }\end{array}$ & [160] \\
\hline & ND & $80-100 \mathrm{~nm}$ & ND & $\mathrm{HBV}$ & $40-50 \%$ & $\begin{array}{l}\text { In vitro, Huh7 liver-derived cells } \\
\text { In vivo, i.v. injection in mice }\end{array}$ & [172] \\
\hline & ND & ND & ND & EphA2 & $\begin{array}{l}50 \% \\
95 \%\end{array}$ & $\begin{array}{l}\text { In vivo, i.p. injection in mice } \\
\text { In vitro, HeyA8 or SKOV3ip1 cells }\end{array}$ & [176] \\
\hline & ND & ND & ND & IL-8 & $32-48 \%$ & $\begin{array}{l}\text { In vitro, HeyA8 and SKOV3ip1 cells } \\
\text { In vivo, i.p. injection in mice }\end{array}$ & [177] \\
\hline & Spherical & $85-90 \mathrm{~nm}$ & ND & HCV IRES & $90 \%$ & In vivo, i.v. injection in mice & [178] \\
\hline & ND & $81-85 \mathrm{~nm}$ & ND & $\begin{array}{l}\text { ZEBOV Lpol., VP24, } \\
\text { VP35 }\end{array}$ & $66 \%$ & In vivo, bolus intravenous infusion, monkeys & [179] \\
\hline & ND & ND & ND & $\begin{array}{l}\text { MARV VP24, } \\
\text { VP35, VP40, NP, Lpol }\end{array}$ & $60-100 \%$ & $\begin{array}{l}\text { In vitro, HepG2 cells } \\
\text { In vivo, i.v. injection in mice }\end{array}$ & [180] \\
\hline \multicolumn{8}{|l|}{ Hydrogels } \\
\hline & Spherical & $7-8 \mu \mathrm{m}$ & $20-30 \mathrm{mV}$ & EGFP & ND & In vitro, HUH7 cells & [182] \\
\hline & Spherical & $\mathrm{Rz} \sim 54 \mathrm{~nm}$ & $<0.3 \mathrm{mV}$ & EGFR & $\sim 35 \%$ & In vitro, Hey, BG-1 cells & [183] \\
\hline & ND & $\sim 100 \mathrm{~nm}$ & ND & EGFR & ND & In vitro, Hey cells & [184] \\
\hline & ND & ND & ND & GFP & $80 \%$ & In vitro, HEK293 cells & [189] \\
\hline
\end{tabular}




\begin{tabular}{|c|c|c|c|c|c|c|c|}
\hline \multicolumn{4}{|c|}{ Nanoparticle systema } & \multirow[t]{2}{*}{ Target gene ${ }^{b}$} & \multirow{2}{*}{$\begin{array}{l}\text { Silencing } \\
(\%) c\end{array}$} & \multirow[t]{2}{*}{ Delivery routed } & \multirow[t]{2}{*}{ Ref } \\
\hline Type & Shape & Size & $\zeta$ potential & & & & \\
\hline & ND & ND & ND & IL-10 & $80 \%$ & In vitro, APCs & [190] \\
\hline & ND & ND & ND & TG2 & $72-92 \%$ & $\begin{array}{l}\text { In vivo, s.c. injection in mice } \\
\text { In vitro, A375SM and MDA-MB231 cells }\end{array}$ & [191] \\
\hline & Irregular & $200-500 \mathrm{~nm}$ & ND & GFP & $66 \pm 8.2 \%$ & In vitro, HCT-116 cells & [192] \\
\hline & ND & $6 \mathrm{~mm}$ & ND & mTOR & $72 \%$ & In vitro, $\mathrm{NIH} 3 \mathrm{~T} 3$ cells & [193] \\
\hline & Spherical & $111 \pm 15 \mathrm{~nm}$ & $36.7 \mathrm{mV}$ & GFP & ND & In vitro, MDA-MB- 435 cell & [194] \\
\hline & ND & $100-400 \mathrm{~nm}$ & ND & GFP/VEGF & $53 \%$ & In vitro, Hela cells and PC-3 cells & [195] \\
\hline \multicolumn{8}{|c|}{ Semiconductor nanocrystals } \\
\hline & Ellipsoid & ND & ND & EGFP & $29 \%$ & In vitro, HeLa cells & [199] \\
\hline & Spherical & $16 \pm 1 \mathrm{~nm}$ & $\sim 21 \mathrm{mV}$ & Her-2 & $65 \%$ & In vitro, SK-BR-3 cells & [203] \\
\hline & Spherical & $17 \mathrm{~nm}$ & $8.5 \mathrm{mV}$ & Human CYPB & 98.19 & In vitro, MDA-MB-231 cells & [204] \\
\hline & Spherical & $200 \mathrm{~nm}$ & ND & VEGF & $29.7 \pm 3 \%$ & In vitro, PC-3 cells & [205] \\
\hline
\end{tabular}

aValues are estimated for nanoparticle delivery system (NP and siRNA) by different techniques, including TEM, SEM, AFM, and DLS for shape and size, while zeta potential for surface charge. ND, not determined; MSNPs, mesoporous silica nanoparticle; MNP, magnetic nanoparticles; MNCs, magnetic nanoclusters; AuNPs, gold nanoparticles; CNTs, carbon nanotubes; PAMAM, polyamidoamine; SWNT, single-walled nanotubes; MWNT, multi-walled nanotubes; G4, generation 4; L, length; D, diameter; PEI, polyethylenimine; PLL, poly-L-lysine; Rz, z-average radii; PEG, poly(ethylene glycol); PPD, PEG-peptide-dioleoylphosphatidyl ethanolamine;

bBcl-2, B-cell lymphoma 2; Pgp, P-glycoprotein; GFP, green fluorescent protein; Luc, luciferase; EGFP, enhanced green fluorescent protein; $\beta$-gal, $\beta$-galactosidase; ERK, extracellular regulated kinase; CXCR4, chemokine receptor type 4; CD4, cluster of differentiation 4; TERT, telomerase reverse transcriptase; VEGF, vascular endothelial growth factor; RFP, red fluorescent protein; periostin; FAK, focal adhesion kinase; PLXDC1, plexin domain containing 1; Src, Sex combs reduced; Fgr, gardner-Rasheed feline sarcoma viral oncogene homolog; HPV16 E7, human papilloma virus 16 E7 gene; PLK-1, polo-like kinase 1; RRM2, ribonucleotide reductase M2; EphA2, EPH receptor A2; $\mathrm{HBV}$, hepatitis B virus; HCV IRES, hepatitis C virus internal ribosome entry site; ZEBOV, Zaire ebolavirus; Lpol, L polymerase; VP, viral protein; MARV, Marburg virus; IL-8, interleukin 8; IL-10, interleukin 10; TG2, tissue transglutaminase; mTOR; mammalian target of rapamycin; Her-2, human epidermal growth factor receptor 2; Human CYPB, human cyclophilin B.

c from its control value

d SVR bag4 is an endothelial cell line; A2780, A2780/AD, A2780ip2, SKOV3ip1, HeyA8 and BG-1 are human ovarian cancer cell lines; KBV1 is human epidermoid carcinoma; SK-BR-3, MCF-7, MDA-MB-435 and MDA-MB231 are human breast cancer cell lines; HEPA-1 is mouse liver cancer cell line; HeLa, CaSki and SiHa cells are human cervical cancer cell line; SHEP is human neuroblastoma cell line; A549, Calu 6 and H1299 are lung cancer cell lines; $4 \mathrm{T1}$ is murine breast cancer cell line; PC-3, human prostate carcinoma cell line; K1 is a Chinese hamster ovary cell line; MDM is human monocyte-derived macrophage cells; PBMCs are peripheral blood mononucleated cells; K562 is chronic myelogenous leukemia cell line; HUH7 and HepG2 are human liver cancer cell lines; B16F10 is murine melanoma cell line; KB is human oral cavity epidermal cancer cell line; MOEC is mouse endothelial cell line; Neuro2A is mouse neural crest-derived cell line; HT1080, human fibrosarcoma cell line; HCT-116 is colonic epithelial cell line; HEK293, human embryonic kidney 293 cell line; APCs are antigen-presenting cells; A375SM is metastatic human melanoma cell line; NIH 3T3 is mouse embryonic fibroblast cells; i.v., intravenous; i.t., intratumorally; i.p., intraperitoneal; s.c., subcutaneous.

Table 4. Advantages and disadvantages of different nanoparticles to siRNA delivery.

\begin{tabular}{|c|c|c|c|}
\hline Nanoparticle & Advantages & Disadvantages & Ref \\
\hline MSNPs & $\begin{array}{l}\text { Large surface area } \\
\text { Stability } \\
\text { Biocompatibility } \\
\text { Tuned biodegrability } \\
\text { Controllable porosity, allows multifunctional and sequential delivery } \\
\text { Surface reactivity, and easy functionalization }\end{array}$ & In vivo toxicity & $\begin{array}{l}{[52,} \\
53, \\
58-63]\end{array}$ \\
\hline MNPs & $\begin{array}{l}\text { Large surface area } \\
\text { Small in size, allows longer circulation and improved tissue penetration } \\
\text { High magnetization for remotely-controlled and fast delivery } \\
\text { Controlled clustering } \\
\text { Potential for multimodal applications (e.g. targeting, diagnostic, and therapy) }\end{array}$ & $\begin{array}{l}\text { Poor colloidal stability } \\
\text { Limited biocompatibility and } \\
\text { Cytotoxicity } \\
\text { Non-biodegradability }\end{array}$ & $\begin{array}{l}{[64,} \\
71-73 \\
83]\end{array}$ \\
\hline AuNPs & $\begin{array}{l}\text { Large surface area } \\
\text { Easy synthesis, modification and bioconjugation } \\
\text { Rational stability and biocompatibility } \\
\text { Potential for multimodal applications (e.g. targeting, diagnostic, and therapy) }\end{array}$ & $\begin{array}{l}\text { High cost of large scale production } \\
\text { Stickiness and limited in vivo stability } \\
\text { Non-biodegradability }\end{array}$ & $\begin{array}{l}{[74,} \\
82,83]\end{array}$ \\
\hline CNTs & $\begin{array}{l}\text { Large surface area } \\
\text { Ultra-high functionalization and loading capacities } \\
\text { High penetration capacity to biological barriers } \\
\text { Ultimate electrical and thermal conductivities and mechanical strength } \\
\text { Encapsulation and storage functions in delivery of molecules }\end{array}$ & $\begin{array}{l}\text { Difficulty in production and handling } \\
\text { Non-biodegradability } \\
\text { Unresolved toxic properties }\end{array}$ & $\begin{array}{l}{[84-86,} \\
108]\end{array}$ \\
\hline Graphene & $\begin{array}{l}\text { Large surface area } \\
\text { Facile synthesis } \\
\text { Colloidal stability } \\
\text { Easy surface functionalization } \\
\text { Good electrical and mechanical properties }\end{array}$ & $\begin{array}{l}\text { High cost and difficultly of massive } \\
\text { production } \\
\text { Non-biodegradability } \\
\text { Increased biosafety concerns }\end{array}$ & $\begin{array}{l}{[100} \\
102 \\
107]\end{array}$ \\
\hline Dendrimers & $\begin{array}{l}\text { Very precise size and shape controllability } \\
\text { Water solubility and biocompatibility } \\
\text { Elicit negligible immune response } \\
\text { Easy electrostatic interaction with nucleic acid and protection from nuclease activity }\end{array}$ & $\begin{array}{l}\text { Non-specific cytotoxicity } \\
\text { Limited release of the associated } \\
\text { bio-actives } \\
\text { Rapid clearance }\end{array}$ & $\begin{array}{l}{[109} \\
110 \\
115]\end{array}$ \\
\hline Polymers & $\begin{array}{l}\text { Easy and cheap production } \\
\text { Fine tenability of structure and properties } \\
\text { Simplicity for loading and complexation with nucleic acid by electrostatic interaction } \\
\text { It can be tailored for a wide range of molecular weights } \\
\text { Natural polymers are nontoxic, biocompatible, and biodegradable. }\end{array}$ & $\begin{array}{l}\text { Limited stability } \\
\text { Synthetic polymers cause cellular } \\
\text { necrosis and apoptosis }\end{array}$ & $\begin{array}{l}{[23} \\
50, \\
117 \\
125 \\
144]\end{array}$ \\
\hline Cyclodextrin & $\begin{array}{l}\text { Low toxicity } \\
\text { Act as molecular containers that can help to enhance biological properties of loaded molecules } \\
\text { Lack of immune stimulation }\end{array}$ & $\begin{array}{l}\text { High cost production } \\
\text { Concerns regarding their safety and } \\
\text { limited solubility }\end{array}$ & $\begin{array}{l}{[150} \\
151 \\
159]\end{array}$ \\
\hline
\end{tabular}




\begin{tabular}{|c|c|c|c|}
\hline & In vivo stability due to the absence of enzyme degradation in humans & & \\
\hline Liposomes & $\begin{array}{l}\text { Biocompatibility } \\
\text { Rapid cellular uptake } \\
\text { The flexibility of synthesis, modification and formulation } \\
\text { Targeting and controlled release } \\
\text { Easy conjugation and functionalization with components such as targeting, contrast agents, } \\
\text { probes, and fluorophores. }\end{array}$ & $\begin{array}{l}\text { High production cost } \\
\text { Limited instability and leakage of } \\
\text { loaded materials } \\
\text { Low solubility } \\
\text { Rapid clearance }\end{array}$ & $\begin{array}{l}{[160,} \\
161 \\
175\end{array}$ \\
\hline Hydrogels & $\begin{array}{l}\text { Tenable synthesis and physicochemical properties } \\
\text { Selective surface-functionalization } \\
\text { High degree of porosity and high loading capacity } \\
\text { Controlled and sustained release into the target tissues } \\
\text { Biocompatibility and biodegradability }\end{array}$ & $\begin{array}{l}\text { High cost production } \\
\text { Instability }\end{array}$ & $\begin{array}{l}{[181} \\
185 \\
188]\end{array}$ \\
\hline Quantum dots & $\begin{array}{l}\text { Size and structure-based tunable emission } \\
\text { High molar extinction coefficient } \\
\text { High photo and chemical stability } \\
\text { Potential for synergistic diagnostic and therapeutic applications }\end{array}$ & $\begin{array}{l}\text { Potential toxicity } \\
\text { Particle aggregation, degradation and } \\
\text { removal }\end{array}$ & $\begin{array}{l}{[199,} \\
200, \\
208]\end{array}$ \\
\hline
\end{tabular}

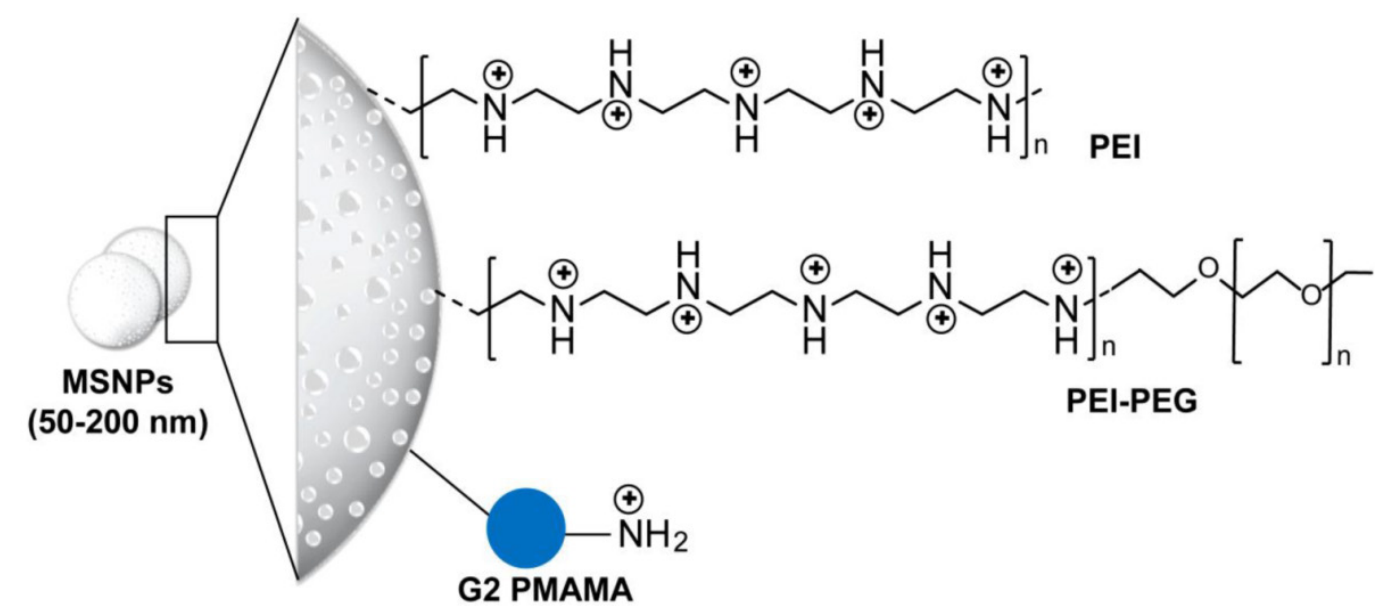

Figure 2. Structure of mesoporous silica nanoparticles applied for delivery of siRNA. Phosphonate-modified mesoporous silica nanoparticles (MSNPs) are further modified using electrostatic attachment of a polyethylenimine (PEI) polymer, which was used for subsequent covalent attachment of poly(ethylene glycol) (PEG) or electrostatic-based loading of siRNA [56,57]. In addition, 3-isocyanatopropyltriethoxysilane (ICP) is utilized for the preparation of generation 2 (G2) amine-terminated polyamidoamine (PAMAM) dendrimers-modified MSNPs. The terminal amino groups of PAMAM are covalently reacted with ICP functional groups on the MSN surface. These dendrimer-modified MSNPs can efficiently complex with siRNAs through electrostatic interaction [54].

\section{I Silica and silicon-based nanoparticles}

Silica and silicon-based delivery systems have emerged in drug delivery applications due to their controllability in nanopore formation and surface modifications. This enabled a multi-component and multi-functional bio-delivery systems that can possibly perform a sequence of functions at various stages of the delivery route $[52,53]$. Several spherical mesoporous silica nanoparticles (MSNPs) with core size range from 50 to $200 \mathrm{~nm}$ and modified with polyethyleneimine (PEI) or PEI- polyethylene glycol (PEG) or polyamidoamine (PAMAM) are applied for siRNA, see Figure 2 for more details on particle structure and surface modifications. This surface layer of cationic polymer or quaternized dendrimers was added to permit the electrostatic loading of the siRNA, while the presence of protective polymer of PEG was showed to improve the cellular uptake and delivery of MSNPs-siRNA conjugates. For example, PAMAM dendrimer-modified MSNPs carrying both doxorubicin (Dox) and B-cell lymphoma 2 (Bcl-2) gene silenc- ing siRNA has been demonstrated to enhance the cytotoxicity of Dox by 64-fold due to the suppression of membrane pumps that mediate drug resistance [54]. Cationic PEI-MSNPs were particularly efficient for transducing mouse hepatoma HEPA-1 cells with a siRNA construct that was capable of knocking down green fluorescent protein (GFP) expression with minimal or no cytotoxicity [55]. Recently, Meng et al. have demonstrated that encapsulation of Dox by mesoporous silica nanoparticles could enhance and restore Dox sensitivity in drug resistant cancer cell lines by codelivery of a siRNA that knockdown P-glycoprotein drug exporter $[56,57]$. It is worth noting that the application of silica nanoparticles are additionally promoted by its intrinsic biocompatibility [55, 58], biodegradability [59], and its efficient bioelimination in vivo $[60,61]$. However, several observations indicating disadvantageous metabolic changes and toxicity especially in vivo have pronouncedly been recorded. These observations were mainly correlated to the particle surface functionalization and the presence of active silanol groups $[62,63]$. 

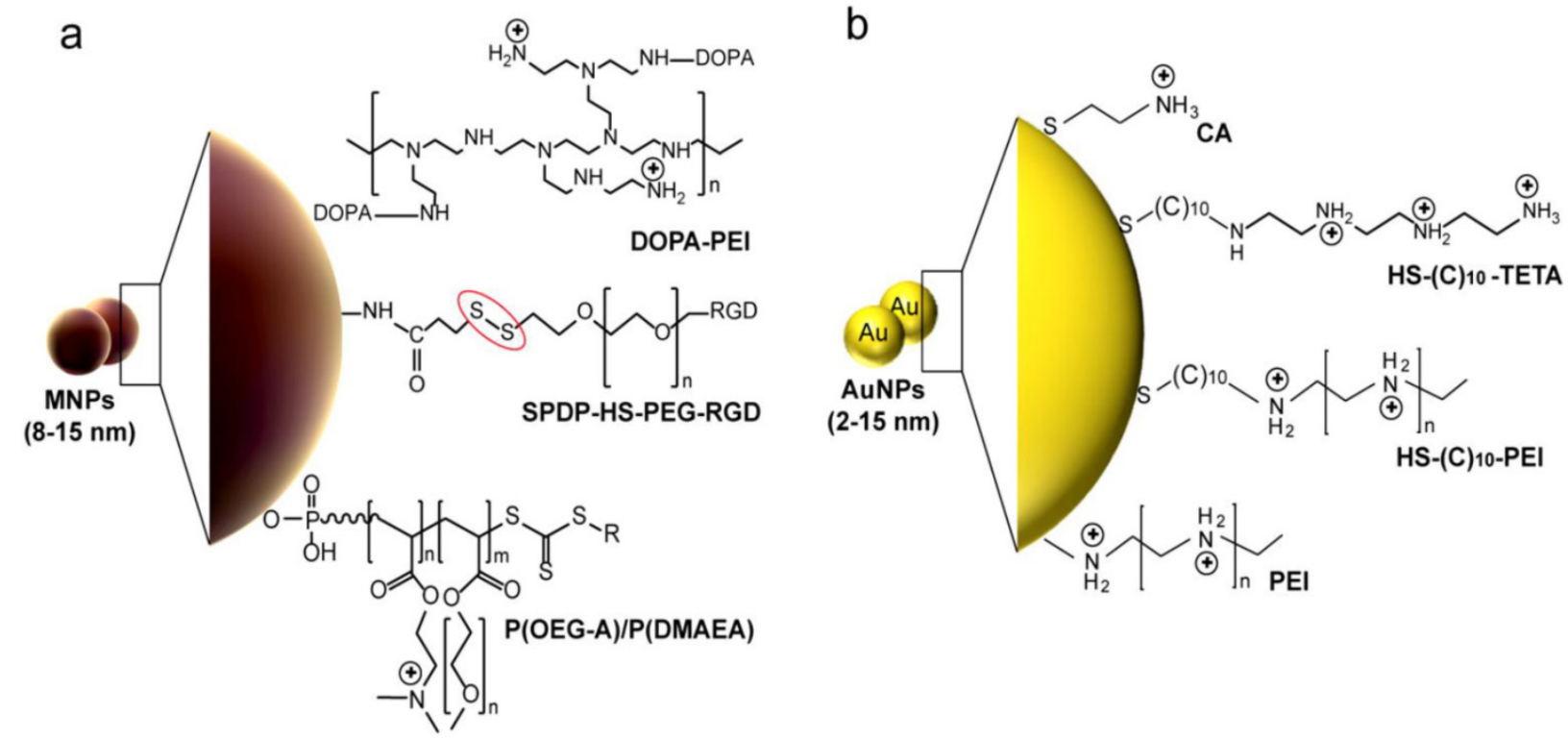

Figure 3. Common surface modifications of metal and metal oxides-based nanoparticles reported in siRNA delivery. (a) Magnetic nanoparticles (MNPs). Branched PEl polymer is utilized for preparation of magnetite nanoparticle clusters (MNCs) $[64,68]$. PEl is directly reacted with MNPs to form stable nanocomplexes or indirectly anchored through the covalent binging to 3,4-dihydroxy-L-phenylalanine (DOPA). N-succinimidyl-3-(2-pyridyldithio)propionate (SPDP) is applied to activate bovine serum albumin (BSA)-MnMEIO nanoparticles. The SPDP-activated MnMEIO nanoparticles are then treated with thiolated poly(ethylene glycol) (PEG) functionalized with a cyclic Arg-Gly-Asp (RGD) peptide, or thiolated siRNA at the distal end (red circle) [67]. MNPs can be coated with two different polymers of poly(oligoethylene glycol) methyl ether acrylate (P(OEG-A)) and poly(dimethylaminoethyl acrylate) (P(DMAEA)). P(DMAEA) forms an internal layer with a slight positive charge for electrostatic immobilization of siRNA and P(OEG-A) forms an outer antifouling shell for long circulation in vivo [65]. (b) Gold nanoparticles (AuNPs). Amine functionalized AuNPs are directly prepared by surface modification with cystamine hydrocholoride (CA) that carries amine-derived positive charge [75]. AuNPs modification with a positive charged polymer layer of PEI [77] or triethylenetetramine (TETA) [79] are reported for the simple electrostatic conjugation and delivery of siRNA. These modifications are commonly accomplished with Au-thiol non-covalent binding through thiol-terminated linkers such as II-mercaptoundecanoic acid [75, 79].

\subsection{Metal and metal oxides nanoparticles}

Different kinds of metal nanoparticles have so far been tested for gene delivery purpose. Among them, magnetic nanoparticles (MNPs) have received increasing attentions owing to their unprecedented capabilities to achieve remotely-controlled transfection by applying an external magnetic field. This process of magnetic-based transfection, referred as magnetofection, is one of the most powerful tools recently reported to enhance gene transfection efficiency. It reduces transfection time via magnetic field and force cellular transport processes [64]. Generally, magnetic nanoparticle intracellular siRNA delivery systems comprise surface polymer layers in order to enhance the siRNA-particle complex formation and their total cellular uptake (Figure 3a). Iron oxide nanoparticles modified with two different polymers, i.e. poly(oligoethylene glycol) methyl ether acrylate and poly(dimethylaminoethyl acrylate) were efficiently applied in siRNA transfection into human neuroblastoma SHEP cells both in the presence and in the absence of a magnetic field [65]. This potential magnetic nanoparticle-based transfection has further been expanded into several multifunctional systems suitable for concurrent targeting, diagnostic and therapeutic applications. A nanovector for siRNA comprised of iron oxide magnetic nanoparticle core coated with PEI, siRNA, and chlorotoxin and possesses dual tar- geting specificity and dual therapeutic effects has also been described for targeted cancer imaging and therapy [66]. Lee et al. developed a cancer-cell-targeted gene silencing system prepared from a magnetic-nanoparticle platform on which a fluorescent dye, siRNA, and a Arg-Gly-Asp (RGD)-peptide targeting moiety were attached [67]. These multifunctional magnetic nanovectors exhibited significant targeting, intracellular uptake and gene silencing effects in cancer cells. On the other hand, magnetic nanocrystal clusters (PMNCs)-cross-linked with PEI were developed to magnetically trigger intracellular delivery of siRNA $[64,68,69]$. Such new nanocomposite carriers are highly controlled clustering structures with multi-nanoparticles cores surrounded by a shell of alkylated PEI $[64,68,70]$. The clustering approach in these composites greatly improves their magnetic responsiveness compared to individual nanoparticles, which provide more enhanced, site-specific and retained release of siRNA [64]. In addition, the presence of PEI shells, with favorable transfection properties of PEI, enables rapid and improved conjugation and transduction efficiency of siRNA molecules. PEI is highly cationic helping condensed electrostatic conjugation of anionic siRNA forming compact polyelectrolyte complexes with siRNA. Also, its role in nucleic acid protection and rapid endocytosis enhances the total delivery efficiency of these systems [71-73]. Park et al. reported 
that the gene silencing effect of siRNA mediated clustering magnetic nanocrystals was considerably higher than that of siRNA complexed with single magnetic nanoparticles [64]. Recently, Chen group validated both magnetic iron oxide [68] and magnesium oxide [70] nanoparticles-based cluster systems for the delivery of siRNA at in vitro and in vivo levels. Their initial results for luciferase siRNA delivery to luciferase transfected 4T1 murine breast cancer (fLuc-4T1) cells, and to a fLuc-4T1 xenograft model concluded the efficiency of the systems to cause significant knockdown of luciferase and demonstrated efficient protection of the loaded siRNA [68, 70].

Other classes of metal nanoparticles for delivering siRNA have been proposed, including the use of gold nanoparticles (AuNPs). Due to their easy synthesis, amenable modification and bioconjugation, and rational stability and biocompatibility, AuNPs have recently been considered as excellent siRNA delivery systems [74]. Thus far, the strategies developed to deliver siRNA by AuNPs can be classified into two categories: 1) siRNA conjugated directly to the AuNP surface via a gold-thiol bond or electrostatic interaction, and 2) siRNA adhered to the AuNP surface modified with polymer layers [75-77]. As shown in Figure 3b, both strategies incorporate PEG, PEI or other passivating molecules to assist in stabilization and/or promoting endosomal escape into the cytoplasm [75, 77, 78]. The polyvalent siRNA/AuNPs conjugates showed a greater half-life and prolonged gene knockdown compared to free RNA duplexes [75-77, 79, 80]. Positively charged AuNPs electrostatically complexed with negatively charged siRNA-PEG conjugates were described by Lee et al. to successfully suppress the expression of GFP within the human prostate carcinoma cells [75]. PEI-capped AuNPs/siRNA that target endogenous cell-cycle kinase, an oncogene polo-like kinase 1 (PLK1), displayed a significant gene expression knockdown in MDA-MB-435s cells, whereas it was not obvious when the cells are treated with PLK1 siRNA using PEI as the carrier [80]. Elbakry et al. proposed layer-by-layer (LbL) assembly of the oppositely charged siRNA and PEI on the surface of AuNPs. The resultant LbL-coated nanoparticles were able to reduce the cellular enhanced green fluorescent protein (EGFP) production to about $28 \%$ in CHO-K1 cells [77]. Also, dendronized PEI AuNPs suppressed $\beta$-gal expression by $\sim 50 \%$ with minimal toxicity [79]. Recently, Reynolds et al. utilized gold nanorods-galectin-1 siRNA complexes to inhibit the gene expression of galectin-1. The prepared siRNA complexes significantly attenuated the expression of methamphetamine potentiates galectin-1 in human monocyte derived macrophages and significantly reduced the effects of metham- phetamine on human immunodeficiency virus type 1 (HIV-1) infection [81]. These applications are generally demonstrating the potentiality of metal nanoparticles for siRNA delivery. However, determining the cytotoxicity and stability of this class of nanoparticle is a recent challenge and more extensive in vivo studies are needed to address several concerns about biocompatibility, biodistribution and tissue accumulation $[82,83]$.

\subsection{Carbon-based materials}

Allotropic nanostructures of carbon nanotubes and graphene nanosheets are hosting enormous interests as shuttle nanovehicles for drug and siRNA delivery applications. Their extremely large surface area, with every atom exposed on its surface, allows for ultra-high functionalization and loading capacities. In addition to excellent material properties such as ultimate electrical and thermal conductivities and mechanical strength, enlarge and intensify their importance for a wide range of biomedical applications [84-87].

Carbon nanotubes (CNTs) are 1-dimentional hollow carbon nanostructures with a typical diameter of 1-2 nm and length ranges from $50 \mathrm{~nm}$ up to $1 \mathrm{~cm}$. This tubular morphology renders them to act as cellular scale nano-needles that are easily and efficiently taken up by cells [88-90]. In the same time, they permit encapsulation of molecules and provide material storage functions as well as protection and controlled release of loaded molecules that are becoming increasingly important in modern delivery applications. Both forms of single-walled (SW) and multi-walled (MW) carbon nanotubes were modified and conjugated with siRNA to be employed against HIV infection and various cancers. Ammonium-functionalization of CNTs and surface modification with cationic polymers such as PEI and poly(diallyldimethylammonium)chloride (PDDA) are commonly applied for simple electrostatic loading of siRNA to their surface (Figure 4). SWCNs grafted with siRNA showed effective silencing activity by $50-60 \%$ to both cluster of differentiation 4 (CD4) receptor and chemokine receptor type 4 (CXCR4) co-receptor of $\mathrm{T}$ cells, which are required for HIV entry into human and infection [91]. Zhang et al. proposed SWCNTs as an efficient vector for siRNA to suppress murine telomerase reverse transcriptase expression in murine tumor cells on both in vitro and in vivo levels [92]. This approach also has been successfully used in the control of key signaling regulators in cancer cells, including suppressors of cytokine signaling 1, cyclin A, and extracellular signal-regulated kinase harnessing the potentiality of SWCNTs to deliver siRNA for cancer therapy [93-95]. 


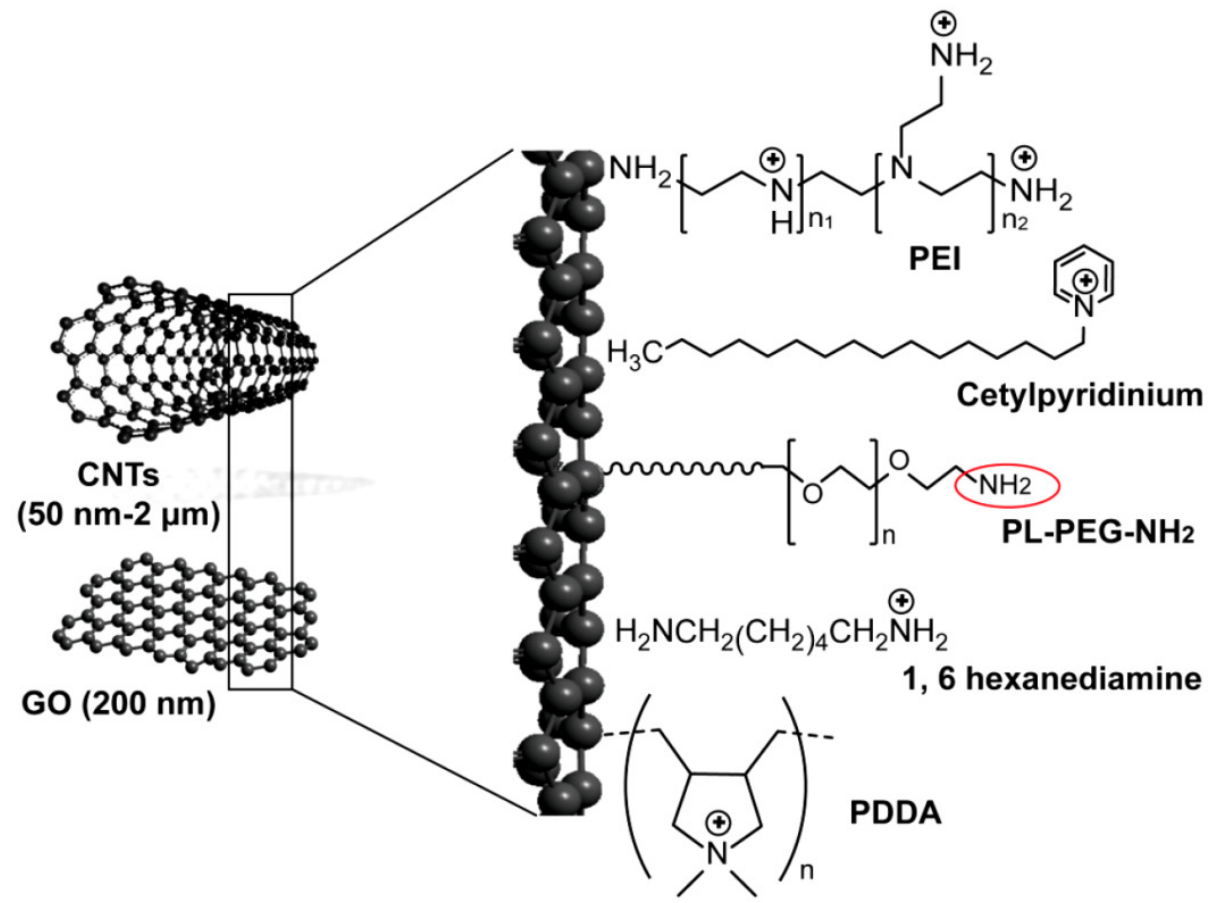

Figure 4. Carbon-based nanoparticles for delivery of siRNA. Applied carbon nanostructures include multiwalledand singlewalled carbon nanotubes (CNTs) and single-atom-thick sheets of graphene oxide (GO). Ammonium-functionalized CNTs are prepared through non-covalent binding with cetylpyridinium chloride [209], tert-butyl-n-(6-aminohexyl)carbamate [92], and I, 6 hexanediamine [95]. Polymer coated-CNTs and GO are prepared through the addition of different positively charged polymers to their surfaces, including polyethylenimine (PEI) [106, 209] and poly(diallyldimethylammonium)chloride (PDDA) [94]. Both ammonium-functionalized CNTs and polymer-coated CNSs are conjugated to siRNA by electrostatic interaction. CNTs can also be modified with non-covalent adsorption of phospholipid molecules carrying poly(ethylene glycol) (PL-PEG) chains with terminal amine or maleimide groups. This amine or maleimide terminal on the PL-PEG (red circle) permits the incorporation of thiolated siRNA by disulfide bond formation [91, 93].

In a recent study, $10-30 \%$ silencing activity of MWCNs-siRNA conjugates have been reported in human lung cancer cell line H12991, and efficient suppression and prolonged survival of an animal model were previously reported in another study by Podesta et al. [96].

Graphene is a newly discovered two-dimensional carbon nanosheet structure [97-99]. It was described to have additional remarkable properties of facile synthesis, high water dispersibility, good colloidal stability, easily tunable surface functionalization, and good biocompatibility that highlight its promise as a novel nano-carrier for safe and efficient gene transfection [100-106]. Recently, its oxidized form of graphene oxide (GO) were used in a pioneering study by Zhang et al. after PEI modification step for sequential delivery of Bcl-2-targeted siRNA and the anticancer drug Dox (Figure 4). The results demonstrated an excellent and effective delivery of siRNA and chemical drugs using GO that significantly enhance the chemotherapy efficacy [106]. The major disadvantage of carbon based nanomaterials to siRNA is their non- biodegradability in vivo that can cause a range of adverse health effects. This point was highlighted in several studies and there is need for more future investigations [107, 108].

\subsection{Dendrimers}

Dendrimers are spherical and symmetrically branched molecules in which branches radiating from a central core molecule and terminating at functional chemical groups depending on the building blocks, such as charged amine in PAMAM dendrimers (Figure 5a,b). Dendrimers have a very precise size and shape defined by the number of generations through controlled chemical synthesis $[109,110]$. Dendrimers are water soluble, biocompatible, elicit negligible immune response, and have been successfully used in DNA and oligonucleotides complexation and delivery [111, 112]. Presumably, nucleic acids were stably incorporated into amine-terminated dendrimers via the interaction of negative charges on the phosphate on the backbone with the high positive charges of the amino groups, thus protected from nuclease activity. Minko group has previously designed and synthesized a surface-acetylated polyamidoamine generation four dendrimer (QPAMAMNHAc) in which surface amine groups are modified with acetyl group and internal tertiary nitrogen are quaternized (Figure $5 c$ ), as a nanocarrier for the targeted intracellular delivery of Bcl-2 siRNA in A2780 human ovarian cancer cells [112-114]. This type of dendrimer has low cytotoxicity and the internal cationic charges for complexation with siRNA to enhance siRNA protection, while the lesser degree of quaternization offers free tertiary amines for potential proton sponge effect $[112,114]$. The same group later was able to achieve a targeting siRNA delivery by the addition of LHRH peptide (Figure $5 c$ ) that further improved internalization of siRNA by cancer cells and significantly enhanced its intracellular activity leading to a substantial silencing of a targeted Bcl-2 gene [114]. They further improved this design by the addition of PEG and poly-L-lysine (PLL) to form a triblock PAMAM-PEG-PLL nanocarrier, see Figure $5 c$. In this design, PEG acts as a linker connecting PLL and PAMAM dendrimers and renders nuclease stability for more protection of siRNA, while PLL enhances the electrostatic interaction with siRNA and also acts as penetration enhancer. This 
triblock carrier showed excellent stability and efficiency to suppress the target Bcl-2 gene [113]. Despite of these applications that generally introduce PAMAM dendrimers as highly efficient delivery vectors with many possible modifications, further addressing of several limitations, including non-specific cytotoxicity, release kinetics of the associated bio-actives and rapid clearance issues is required to initiate in vivo applications $[109,115]$.

\subsection{Polymers (polycations, micelles)}

Polymers offer a great promise because their unit-by-unit construction allows for fine-tuning of the properties required for efficient transfection and release of nucleic acids. Their role as carriers for siRNA delivery was extensively reviewed [23, 116, 117], and currently there is a large number of natural and synthetic polymers is already investigated. Natural polymers, such as cationic polypeptides [118-121], chitosan $(\mathrm{CH})$ [122-126], poly(lactic acid-co-glycolic acid) [127-129] and atelocollagen [130-133] have been used due to their nontoxic, biocompatible, and biodegradable properties. Among available natural polymers, chitosan, which is a linear polymer composed of $\beta$-(1-4)-2-amino-2-deoxy-D-glucopyranose units (Figure 6a), has been most commonly developed for in vitro and in vivo delivery of siRNA [122]. siRNA electrostatically incorporated into chitosan nanoparticles (siRNA/CH-NP) successfully delivered siRNAs against POSTN, FAK and Src family in animal model of ovarian cancer $[123,124]$. Malhotra et al. described a novel method for preparing PEGylated chitosan nanoparticles by chemically modifying C6 position of its repeating units with PEG and the amine groups at the C2 position of the chitosan were protected using phthalic anhydride. This conjugated nanoparticle delivered siRNA with no toxicity in neural cells. Also, several chitosan-based siRNA formulations were proposed for silencing the expression of human papilloma virus (HPV) E6/E7 oncogenes in human cervical cells. The electrostatic complexation of chitosan with HPV16 E7 siRNA efficiently helped to deliver siRNA into CaSki cervical carcinoma cells and was observed to induce apoptosis of cells [125]. A PEI-introduced chitosan-shell/ poly methyl methacrylate-core nanoparticle was also able to efficiently suppress the expression of HVP oncogene in the SiHa human cervical cancer cells [126].

On the other hand, synthetic polymers applied to siRNA delivery include branched or linear PEI, PLL (two of the most common synthetic polycations), PEG, dimethylaminoethyl methacrylate, polyfluorene and cyclodextrin-based polycations (CDP). Among those synthetic polymers, PEIs, is a class of extensively used cationic polymers, with a wide range of molecular weights and many protonable amino groups, leading to a high cationic charge density at physiological $\mathrm{pH}$, see Figure $6 \mathrm{~b}$. However, synthetic polymers like PEI and PLL can trigger cell death through necrosis and apoptosis [134] causing toxicity in living cells. This toxicity is also associated with higher polymer molecular weights and increasing branching. The effect can be reduced by using block copolymers containing PEG and a polycation block [135].
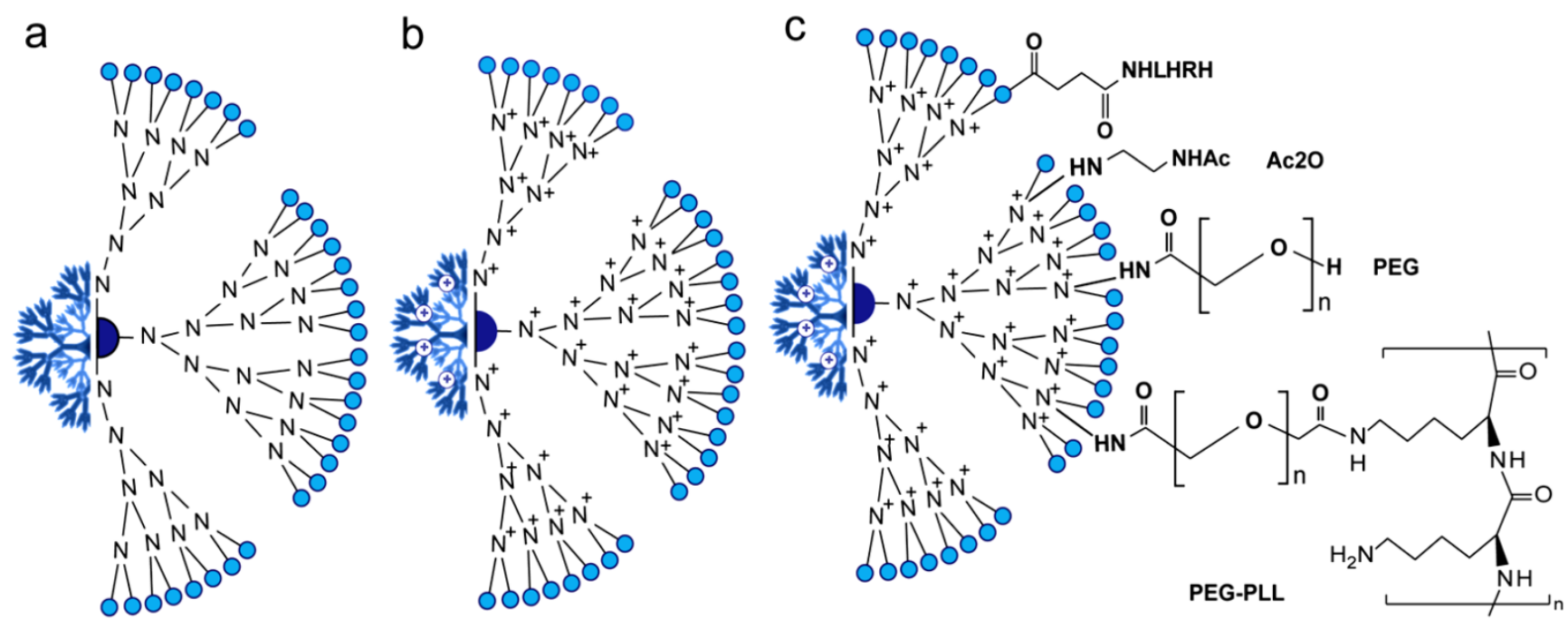

Figure 5. Composition of the PAMAM delivery systems of siRNA. (a) Generation 4 PAMAM-OH dendrimer. (b) Internally quaternized PAMAM to form QPAMAM-OH dendrimer with inner cationic charges. PAMAM are frequently quaternized by methyl iodide (ICH3) and the terminal surface become very positive allowing the efficient electrostatic binding/loading of negatively charged backbone of siRNA. (c) QPAMAM with different surface modifications, including the addition of acetyl group by direct reaction with acetic anhydride (Ac2O) [ I I 2], poly(ethylene glycol) (PEG) and poly-L-lysine (PLL) [II3], LHRH peptide [II4]. This addition of polymer structures such as PEG and PLL is reported to enhance the surface positive charge and circulation of PAMAM nanoparticles. While, the conjugation to LHRH peptides confers targeting ability in PAMAM based delivery applications. 
a
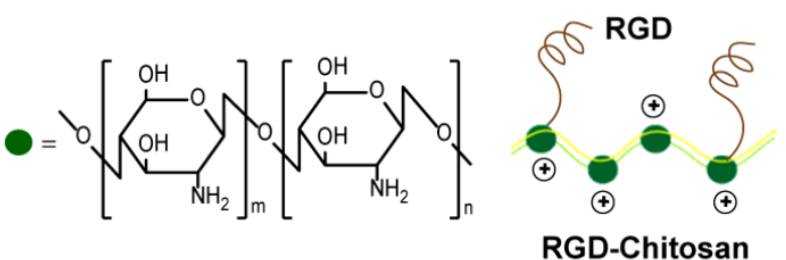

RGD-Chitosan b

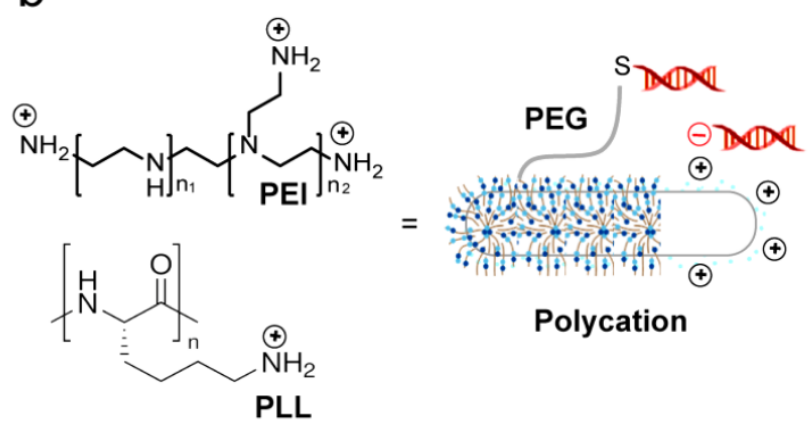

d

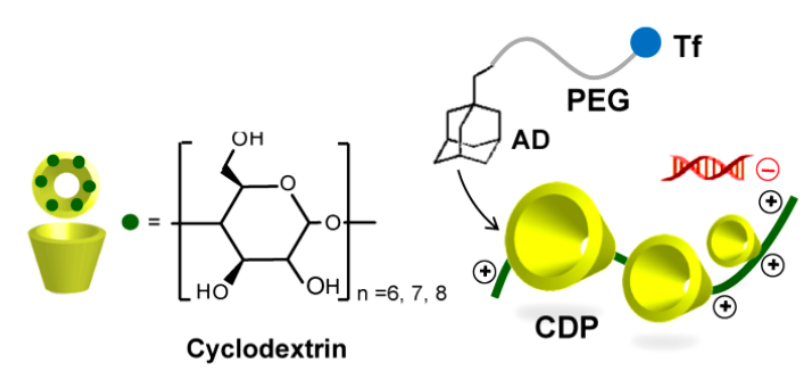

Figure 6. Common polymer based siRNA delivery systems. (a) Chitosan systems. The RGD modified chitosan nanoparticles (RGD-CH-NP) are reported for targeting siRNA delivery. siRNA/RGD-CH-NPs are prepared based on ionic gelation of anionic tripolyphosphate and siRNA [123, I24]. (b) Polycations prepared from polyethylenimine (PEI) or poly-L-lysine (PLL). Their highly cationic nature facilitate strong electrostatic interactions with the negatively of siRNA. PEGylation of polycations with PEG modified with heterobifunctional N-succinimidyl 3-(2-pyridyldithio)propionate allow subsequent coupling of thiolated siRNA via the N-terminal cysteine [I36]. (c) Micelle-based nanoparticles. Micelles are prepared from the triblock copolymer poly(ethylene glycol)-poly(n-butyl acrylate)-poly(2-(dimethylamino)ethyl methacrylate) (PEGPnBA-PDMAEMA). The presence of amine groups on PDMAEMA allows the electrostatic complexation with siRNA [138]. (d) Cyclodextrin containing polymer (CDP). A commonly reported targeted CDP system is prepared through the addition of adamantane-polyethylene glycol-transferrin (AD-PEG-Tf) [153, I55, I57, I58].

The advantage of polymer-based delivery lies in the unparalleled simplicity for formulation of siRNA and polymer complexes. Cationic polymers with high positive charge usually self-assemble into uniform micellar, polycationic nanoparticle complexes with negatively charged siRNA upon simple mixing (Figure $6 \mathrm{a}-\mathrm{c})$, which is driven by electrostatic interactions [116, 136-138]. However, despite this advantage, the electrostatically formed polymer-siRNA complexes are often loose and unstable in vivo. This is due to the low charge density of short double stranded siRNA and the subsequent inability to form robust particles with cationic polymer carriers. Recently, several approaches have been proposed to improve the stability of the formed complexes through the use of polymerized siRNA with a high charge density and chemical crosslinking of the complexes [50, 139, 140]. Following these approaches, Mok et al. utilized the multimerized siRNA that possesses increased charge densities to produce more stable and compact polyelectrolyte complexes with less cytotoxic cationic carriers than naked siRNA [139]. While, Naito et al. utilized phenylboronate with its capability to form reversible covalent esters with 1,2- or 1,3-cis-diols exist on the ribose ring of nucleic acids to assist stabilizing siRNA-polyion complex micelles for intracellular controlled release of siRNAs [49]. Currently, the disulfide-based crosslinking is particularly interesting approach widely reported to enhance the stability and delivery efficiency of many polymeric carriers. Based on the redox potential gradient existing between extracellular and intracellular environments, this strategy was further tailored to provide a capability for selective and controlled release of siRNA in the cytosolic space of target cell [141, 142]. Several studies have reported the utilization of bioreducible PEI and PEG-based carriers for siRNA. Chung et al. indicated that the reducible dimerized siRNAs showed far enhanced complexation behaviors with cationic polymers of PEI or PEG as compared to monomeric siRNA at the same ratio. The reducible siRNA dimeric conjugates showed greatly enhanced cellular uptake and gene silencing effects in vitro. These results were mainly explained to be due to the higher charge density and promoted chain flexibility of the dimerized siRNAs that provide more compact and stable siRNA complexes [143]. Also, a bioreducible PEI complexed with VEGF-siRNA was successful to reduce the level of VEGF protein in HepG2 human liver carcinoma cells in vitro and to inhibit HepG2 tumor growth in a xenograft mouse model. An important recent approach involved the combined use of bioreducible PEI 
with a polymerized siRNA (poly-siRNA) was suggested for more enhanced delivery and gene silencing. The poly-siRNA/PEI complexes exhibited a superior intracellular uptake by murine melanoma cells accompanied with red fluorescent protein (RFP) gene silencing efficiency of about $80 \%$, compared to untreated cells [144]. Furthermore, several other polymers, including poly( $\beta$-amino ester)s [145], arginine conjugated poly(cystaminebisacrylamide-diaminohexane) [146], hyaluronic acid-graft-poly(dimethylaminoethyl ethacrylate) [147], and dextran [148] were investigated as bioreducible siRNA carrier for efficient gene silencing in various human cancer cell lines, see Table 3 . The overall, results suggest their potentiality for the tumor-targeted delivery of siRNA. Most recently, this bioreducible polymer-based strategy for siRNA-carrier complex stabilization was combined with different delivery technologies such as microbubbles, and ultrasound to construct a multimodal delivery system, which successfully synergizes the advantages of each delivery approach to significantly enhance the siRNA uptake and activity in vitro and in vivo [149].

\subsection{Cyclodextrin}

Cyclodextrins (CDs) are a group of cyclic (a-1,4)-linked oligosaccharides of a-d-glucopyranose containing a relatively hydrophobic central cavity and a hydrophilic outer surface. CDs form water-soluble inclusion complexes with many poorly soluble drugs. Thus, CDs are widely used in pharmaceutical formulations, and as such, their long-term biocompatibilities are defined in humans [150,151]. Because of the low toxicity, the lack of immune stimulation, and the absence of enzyme degradation in humans of cyclodextrins, they were chosen as one of the building blocks for the cyclodextrin-containing polymer component. Cyclodextrin-containing polycation nanoparticles can self-assemble with siRNA to form colloidal particles (Figure 6d). The first targeted delivery of siRNA in a human was accomplished with cyclodextrin nanoparticle formulation denoted as CALAA-01 consisting of CDP, which is the main feature of the delivery system, a PEG steric stabilization agent, siRNA against RRM2 gene and human transferring to transferrin receptors for targeted delivery [122, 124, 152-157]. Once approved for use, the four component formulation is self-assembled into $70 \mathrm{~nm}$ nanoparticles in the pharmacy and administered intravenously to patients with advanced solid tumors [152-158]. Despite of this wide reputation of cyclodextrins in drug delivery applications, their large-scale commercial is limited by their high cost and concerns regarding their safety [159].

\subsection{Lipid-based nanoparticles}

Liposomes are among the most advanced nanoparticle drug delivery systems successfully applied in the clinic [160-163]. Several liposomal formulations have been approved by FDA and many more with enhanced features such as stabilized chemotherapeutics encapsulation and tumor-specific targeting versions are currently in development or in clinical trials [164-166]. Liposomes are controlled self-assembly of amphiphilic lipids that form a spherical unilamellar lipid bilayer enclosing an aqueous interior for encapsulation of drug or functional agents (Figure 7). Hydrophobic drugs like paclitaxel can be embedded in the lipid bilayers. Lipid nanoconstructs have also been successfully used in gene delivery. For example, cationic lipids and oligonucleotides complexes have shown good in vivo properties as those with stealth liposomes [167]. The flexibility of liposome functionalization allows control over multiple aspects of the formulation. For example, the charge balance can be tuned by the selection of lipid components, as many cationic lipids suitable for nucleotide complexation are available [168]. Figure 7a shows the structure of the most common lipid types reported in siRNA delivery. The composition of lipid bilayers can be chosen to present specific transition temperatures that determines their mechanical rigidity and fluidity in specific temperature range. This has allowed for post-insertion of targeting component, such as human epidermal growth factor receptor 2 (HER2)-targeted single-chain variable fragment (scFv)-PEG-1,2distearoyl-sn-glycero-3-phosphoethanolamine (DSPE) to form ad hoc immunoliposomes [169]. Conjugation of functionalized lipids makes liposomes a derivatizable carrier for functional components, such as targeting, contrast agents, probes, and fluorophores, see Figure $7 \mathrm{~b}$ that represents schematic structure of liposome-based nanoparticle and possible modifications with different functional moieties. PEGylation, i.e., incorporation of PEG chains, is a commonly adapted strategy for prolonging in vivo circulation. The PEG chains incorporated in Doxil and most liposomal formulations is around 4-8 $\mathrm{mol} \%$. Although the advantages of PEGylation is apparent especially in improving the tumor deposition, the potential down side includes increased difficulty in cell uptake and release of siRNA once in the cellular environment due to inhibition of intracellular trafficking, which is referred to as the PEG dilemma [170]. Hatakeyama et al. thus developed a tumor-specific cleavable PEG-lipid to overcome this problem [160]. A PEG-peptide1,2-dioleoyl-sn-glycero-3-phosphatidylcholine that is cleaved in a matrix metalloproteinase-rich environment was incorporated into a lipid-based multifunctional envelop-type nano device. Similarly, Yingyuad 
et al. prepared putative enzyme-triggered PEGylated siRNA-nanoparticles through using PEG2000peptidyl lipids with peptidyl moieties sensitive to tumor-localized elastase or matrix metalloproteinase-2 digestion [171]. Another type of triggered siRNA-nanoparticle system was described by Carmon $e t$ al. to specifically knockdown hepatitis B virus (HBV) replication in cell culture and in murine hydrodynamic injection models in vivo. The described system is generated by the condensation of siRNA with cationic liposomes to form core particles subsequently post-coupled with PEG. In this system, the step of PEG coupling was included to facilitate acidic $\mathrm{pH}$-triggered release of siRNA from endosomes in the target infected cells to suppress HBV [172].

The charged lipids have been initially used widely for siRNA packaging, simulating the success in DNA formulation [173, 174], one of the main challenges has been the concern over toxicity of cationic components and lipids [175]. Therefore, efforts have been made in the development of neutral lipids for the stable association and delivery of siRNA. siRNA encapsulated in neutral liposomes for RNA interference reported by Sood et al. is among the more successful examples thus far. They proved conclusively that the neutral liposome 1,2-dioleoylsn-glycero-3phosphatidylcholine-encapsulated siRNA targeting the oncoprotein EphA2 and proangiogenic cytokine interleukin 8 (IL-8) were highly effective in reducing in vivo target gene expression in an orthotopic mouse model of ovarian cancer [176, 177]. In addition, several studies reported the application of neutral lipids for siRNA delivery against viruses. A multicomponent lipid nanoparticles (LNPs) system comprising a mixture of titratable amino lipids (DLin-MP-DMA), PEG lipids (PEG-CDMA), and neutral lipids (cholesterol and dipalmitoylphosphatidylcholine) was described for fully encapsulating short synthetic hairpin RNAs (sshRNAs) that target the internal ribosome entry site of the hepatitis $\mathrm{C}$ virus (HCV). This system showed the efficacy of sshRNA against the HCV genome in reducing HCV infection in vivo [178]. Stable nucleic acid-lipid particles (SNALPs) were also successfully utilized by Geisbert et al. to deliver antiviral siRNA constructs to challenge viral infections of Zaire Ebola virus (ZEBOV) and Marburg virus (MARV). A combination of modified siRNAs targeting the ZEBOV L polymerase (Lpol), viral protein (VP) 24 (VP24), and VP35 formulated in SNALPs were able to protect the tested non-human primate model from lethal ZEBOV infection [179]. For MARV, the treatment with different siRNA targeting MARV VP24, VP35, VP40, NP, and Lpol genes formulated in SNALPs resulted in $60 \%-100 \%$ survival of guinea pigs infected with MARV [180].

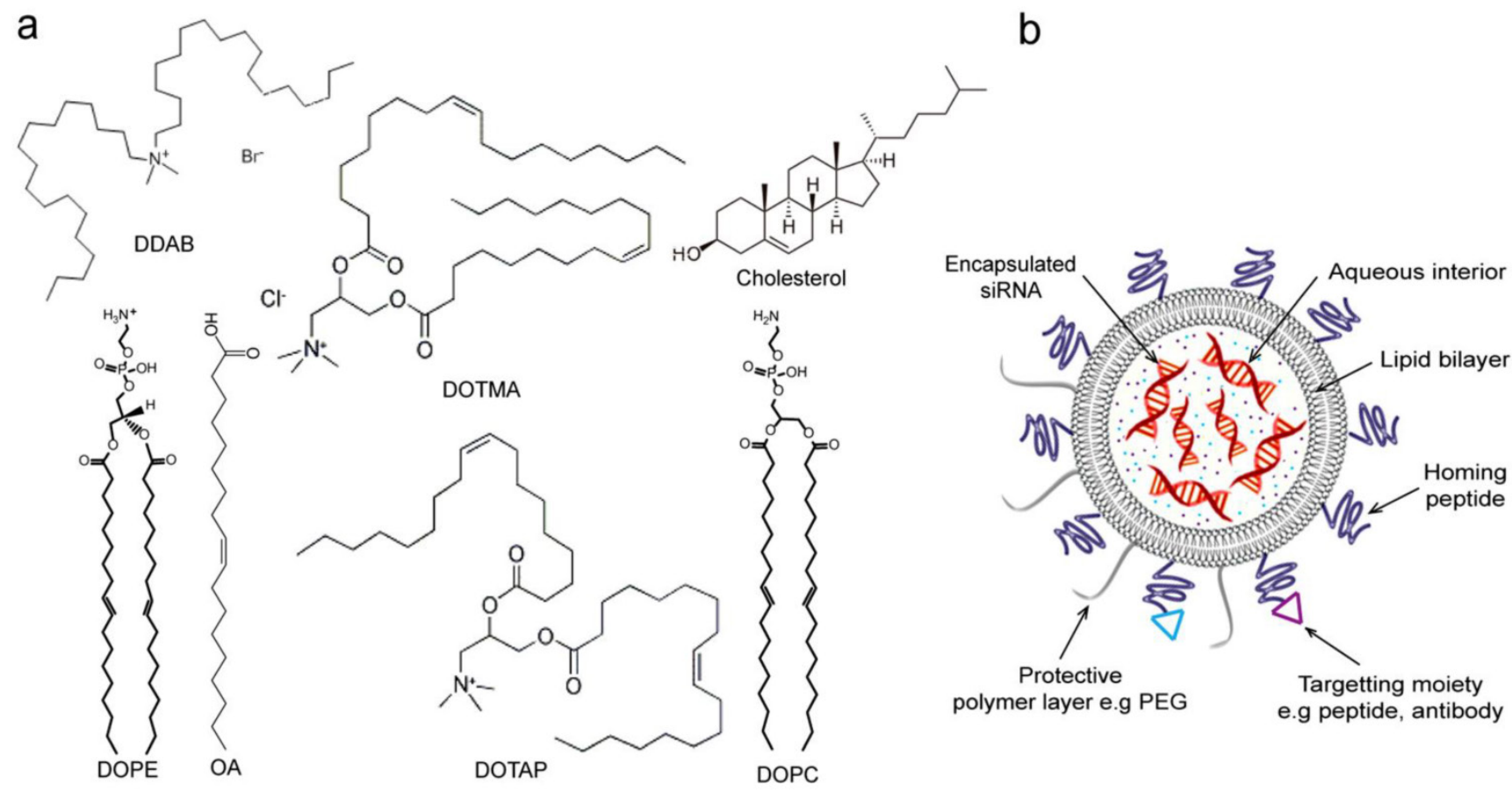

Figure 7. Lipid-based nanoparticles for delivery of siRNA. (a) Common lipid types and structures reported in siRNA delivery. Cationic lipids include dioleoylphosphatidyl ethanolamine (DOPE), oleic acid (OA) [173], dimethyldioctadecylammonium bromide (DDAB), N-[I-(2,3-dioleyloxy)propyl]-N,N,N-trimethylammonium chloride (DOTMA), I,2-dioleoyl-3-(trimethyammonium) propane (DOTAP) [167]. Neutral lipids include I,2-dioleoyl-sn-glycero-3-phosphatidylcholine (DOPC)[I76, I77] and cholesterol [ 173]. (b) A schematic showing lipid-based nanoparticle, e.g., liposome. siRNA molecules are encapsulated in the aqueous interior of liposome. Liposome nanoparticles can additionally carry surface protective polymer layer (e.g. PEG) and cellular receptor-specific moieties such as homing peptides and antibodies for enhanced targeting delivery. 


\subsection{Hydrogels}

Hydrogels can be defined as three-dimensional networks of responsive polymer materials that are hydrophilic in nature and able to retain large amounts of water or biological fluids. They may exhibit different geometries like macroscopic, microscopic or nano-gels [181, 182]. Both macro- and micro-hydrogel particles were previously prepared and applied for siRNA delivery [182-184]. Nanogels are of current intensive investigations for its nanobased enhanced biomedical application [181, 182]. Due to their characteristic biocompatibility and biodegradability, hydrogels offer excellent opportunities for development of a wide range of controlled siRNA delivery strategies [181, 185-187]. Of particular interest in delivery applications, hydrogels that possess a high degree of porosity, permitting a high loading capacity of siRNA, and can also be selectively surface-functionalized to enable specific targeting applications. Moreover, hydrogel delivery could control and tailor siRNA release time into the target tissues by adjusting the physicochemical properties of gel matrices [182]. This advantage offer great chances for sustained delivery, which has been extensively reported to be necessary for efficient gene silencing by siRNA, and considered as a major disadvantage of the other nanoparticulate siRNA delivery systems that rapidly dispersed in tissues [188].

Naked siRNA have been encapsulated and delivered by multiple hydrogel systems, including alginate [189], collagen [189], dextran [182, 190], polyacrylamide [183, 184], chitosan [191], hyaluronic acid (HA) [192], PEG [193], PEI-catechol [194], and PEI/pluronic [195], see Table 3 and Figure 8a,b. Alginate and collagen were formulated by Krebs et al. into hydrogel macro-particle systems that were then successfully applied for localized and sustained delivery of siRNA [196]. Dextran hydrogels loaded with siRNA were adapted to target EGFP in HUH7 human hepatoma cells [182]. Also, Singh et al. presented an in-situ crosslinkable, injectable formulation containing dendritic cell (DC)-chemo-attractants and dual-mode DNA-siRNA loaded dextran microparticles to attract immature DCs and simultaneously deliver, to the migrated cells, immunomodulatory siRNA and plasmid DNA antigens [190]. Peptide-labeled core/shell hydrogel nanoparticles of poly( $\mathrm{N}$-isopropylmethacrylamide) with a high loading capacity for siRNA have been developed and effectively targeted to ovarian carcinomas by receptor-peptide binding (Figure 8a). The encapsulated siRNA is transported into the cell interior, where it is available for epidermal growth factor receptor (EGFR) gene knockdown [183]. This approach was similarly applied by the same group as effective strategy for the sensitization of ovarian cancer cells to taxane chemotherapy [184]. Chitosan hydrogel (CH-HG) is another type of particular importance for siRNA applications due to its low toxicity and irritation effects. In another study, $\mathrm{CH}-\mathrm{HG}$ loaded with either tissue transglutaminase (TG2) siRNA/CH-HG or docetaxel plus TG2 siRNA/CH-HG were effectively delivered in mice bearing A375SM and MDA-MB231 tumors showing enhance localized therapeutic efficacy without risk for systemic side effects [191]. Hyaluronic acid is a naturally occurring nonsulfated glycosaminoglycan polysaccharide, and known to be involved in many biological functions [197]. Hydrogel nanosystems fabricated from HA and physically entrapped GFP siRNA were readily taken up by $\mathrm{HA}$ receptor positive HCT-116 cells, and showed a significant extent of GFP gene silencing in both serum and non-serum conditions [192]. In a trial by Takahashi et al. to mitigate the soft tissue implant foreign body response by suppressing fibrotic responses around implants; siRNA/branched-PEI complexes released from PEG-hydrogel were applied to inhibit the expression of mammalian target of rapamycin (mTOR) in fibroblasts. This trial resulted in mTOR knock-down and subsequent $70 \%$ inhibition in fibroblast proliferation [193]. Similarly, PEI conjugated with catechol groups [194] or crosslinked pluronic acid [195] was adopted by several groups to produce nanogel systems, which were used as a new class of siRNA delivery carriers. The thermally responsive pluronic/PEI system is most interesting. It exhibits a thermally reversible swelling/deswelling volume expansion behavior was synthesized and used for siRNA delivery (Figure $8 b$ ). This thermal responsive behavior interestingly allowed for efficient cellular uptake and effective endosome breaking, and a subsequent enhanced delivery for the electrostatically loaded siRNA-PEG on its surface. Recently, Hong et al. conducted the first attempt to prepare biologically active siRNA-based microhydrogels using sense/antisense complementary hybridization between single-stranded linear and Y-shaped trimeric siRNAs. These siRNA microhydrogels interestingly exhibited super cellular uptake efficiency and gene silencing activity [198].

\subsection{Semiconductor nanocrystals}

The superior and unique physical and photonic characteristics of semiconductor quantum dots (Qdots), including size and structure tunable emission, high molar extinction coefficient, and high photo and chemical stability propelled them in a plethora of imaging applications [199-202]. Building efficient delivery systems generally involves the synergistic use of diagnostic and therapeutic tools. In this context, 
Qdots attracted the interest by being a new generation of nanoparticle carriers that allows real-time fluorescent, multiplexed imaging and efficient delivery of therapeutic agents in living cells [203-207]. Using a PEGylated Qdot core as a scaffold for siRNA and tumor-homing peptides (F3), targeted Qdots conjugates were prepared for siRNA delivery. Delivery of these F3/siRNA-Qdots to EGFP gene-transfected HeLa cells and release from their endosomal entrapment led to significant knockdown of EGFP signal [206]. Also, Qdots modified with different polymers (e.g., amphipols and proton-sponge) were specifically designed for real-time imaging and delivery of siRNA. The polymeric-Qdots systems addressed longstanding barriers in siRNA delivery such as cellular penetration, endosomal release, carrier unpacking, and intracellular transport and showed enhanced silencing activities [203, 204]. Through a FRET based assay, Lee et al. recently utilized cationic Qdots in complex with siRNA for studying intracellular trafficking, unpacking, and gene silencing proving the advances brought by using the photonic properties of Qdots in exploring siRNA delivery processes [205]. Despite of these reports on the apparent applications of Qdots in siRNA delivery, potential problems may arise in their in vivo applications. Among these problems, the toxicity of Qdots is a major issue. Their surface coating can be cytotoxic such as mercaptoacetic acid [200, 208]. Also if this coating are compromised, the metallic core made of cadmium and selenium can be highly toxic [208]. Other issues, including particle aggregation, degradation and removal within the body are still largely unknown [200].

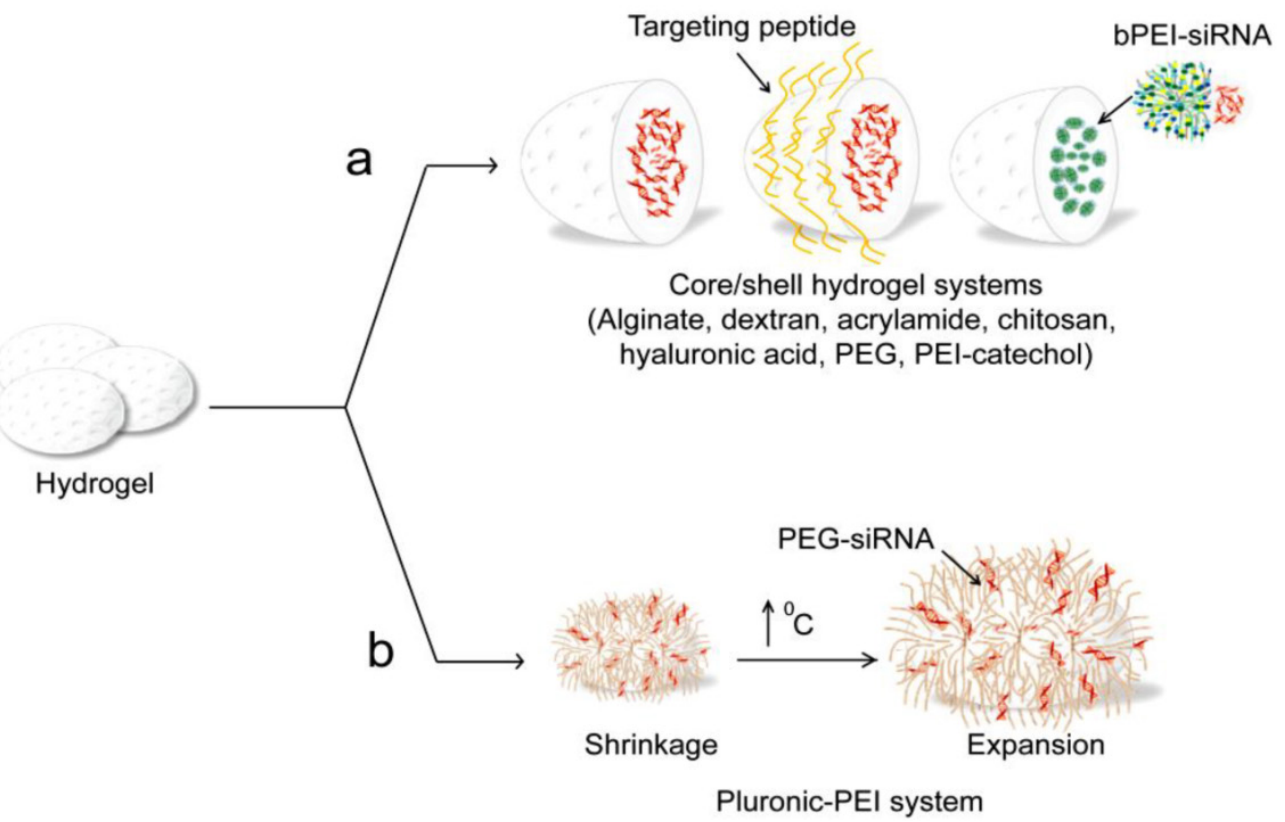

Figure 8. Hydrogel based siRNA delivery systems. (a) Different core/shell hydrogel systems, including alginate [189], dextran [182], acrylamide [183, 184], chitosan [189, 191], poly(lactide-co-glycolide) (PLGA) [190], hyaluronic acid [192], PEG [193], poly(ethylenimine) (PEI)-catechol [194] are reported for siRNA delivery. These systems are physically encapsulating, where siRNAs are incorporated in the hydrogel network based on electrostatic interaction or non-covalent binding. (b) Thermally responsive pluronic/PEl system [195].

\section{Concluding remarks}

siRNA therapeutics have great potential to impact the future of medicine and, it is recently acclaimed as a revolutionary class of drug molecules. However, there are still many challenges and barriers to achieve their full potential. Systemic delivery is one of the most important challenges. Nanoparticles-mediated delivery is a rapidly emerging and potentially powerful technology. Different nanoparticle systems offer various advantages and disadvantages based on their composition, physical, and chemical characteristics, thus leading to a range of effectiveness when associated with siRNA. Silica nanoparticles, due to their controllable porosity, allow multi-functional sequential delivery. The metal nanoparticle cores provide multiple functions, including targeted concentration to cells or tissues, multiplexed imaging and real-time tracking. Carbon nanostructures with every atom exposed on its surface hold ultra-high surface modification and loading capacities. The flexibility of liposome functionalization allows control over multiple aspects of the formulation. On other, hydrogels possess a high degree of porosity and biodegradability that permit a high loading capacity and excellent opportunities for development of different controlled delivery strategies. Polymers are rather unique in their unit-by-unit construction that allows for fi- 
ne-tuning of the properties required for efficient transfection and release. Here, most of the reported studies were successful in implying these unique advantages of nanoparticles to overcome the known siRNA delivery barriers and to enhance the efficiency of siRNA delivery. However, the overall success has been limited to date by toxicity observations and additional challenges associated with many stages along the delivery process. The development of novel nanoparticles and multifunctional nanostructures that display diverse functionalities to achieve effective multimodal delivery applications and advanced studies to reveal the detailed biological aspects concerning siRNA delivery will greatly help our understanding for this process and subsequently help the design of better delivery systems to reach the full potential of siRNA therapeutics.

\section{Competing Interests}

The authors have declared that no competing interest exists.

\section{References}

1. Fire A, Xu S, Montgomery MK, Kostas SA, Driver SE, Mello CC. Potent and specific genetic interference by double-stranded RNA in Caenorhabditis elegans. Nature. 1998; 391: 806-811.

2. Waterhouse PM, Graham MW, Wang MB. Virus resistance and gene silencing in plants can be induced by simultaneous expression of sense and antisense RNA. Proceedings of the National Academy of Sciences of the United States of America. 1998; 95: 13959-13964.

3. Misquitta L, Paterson BM. Targeted disruption of gene function in Drosophila by RNA interference (RNA-i): a role for nautilus in embryonic somatic muscle formation. Proceedings of the National Academy of Sciences of the United States of America. 1999; 96: 1451-1456

4. Wianny F, Zernicka-Goetz M. Specific interference with gene function by double-stranded RNA in early mouse development. Nat Cell Biol. 2000; 2: 70-75.

5. Elbashir SM, Harborth J, Lendeckel W, Yalcin A, Weber K, Tuschl T. Duplexes of 21-nucleotide RNAs mediate RNA interference in cultured mammalian cells. Nature. 2001; 411: 494-498.

6. Bernstein E, Caudy AA, Hammond SM, Hannon GJ. Role for a bidentate ribonuclease in the initiation step of RNA interference. Nature. 2001; 409: 363-366.

7. Lee YS, Nakahara K, Pham JW, Kim K, He Z, Sontheimer EJ, et al. Distinct roles for Drosophila Dicer-1 and Dicer-2 in the siRNA/miRNA silencing pathways. Cell. 2004; 117: 69-81.

8. Zamore PD, Tuschl T, Sharp PA, Bartel DP. RNAi: double-stranded RNA directs the ATP-dependent cleavage of mRNA at 21 to 23 nucleotide intervals. Cell. 2000; 101: 25-33.

9. Nykanen A, Haley B, Zamore PD. ATP requirements and small interfering RNA structure in the RNA interference pathway. Cell. 2001; 107: 309-321.

10. Kim VN, Han J, Siomi MC. Biogenesis of small RNAs in animals. Nat Rev Mol Cell Biol. 2009; 10: 126-139.

11. Hutvagner G, Zamore PD. RNAi: nature abhors a double-strand. Curr Opin Genet Dev. 2002; 12: 225-232.

12. Provost P, Dishart D, Doucet J, Frendewey D, Samuelsson B, Radmark O. Ribonuclease activity and RNA binding of recombinant human Dicer. EMBO J. 2002; 21: 5864-5874.

13. Chin K, DeVries S, Fridlyand J, Spellman PT, Roydasgupta R, Kuo WL, et al. Genomic and transcriptional aberrations linked to breast cancer pathophysiologies. Cancer cell. 2006; 10: 529-541.

14. Xu J, Chen Y, Olopade OI. MYC and Breast Cancer. Genes \& cancer. 2010; 1 : 629-40.

15. Onel K, Cordon-Cardo C. MDM2 and prognosis. Molecular cancer research : MCR. 2004; 2: 1-8.

16. Clark SJ. Action at a distance: epigenetic silencing of large chromosomal regions in carcinogenesis. Hum Mol Genet. 2007; 16: 88-95.

17. Furney SJ, Gundem G, Lopez-Bigas N. Oncogenomics methods and resources. Cold Spring Harbor protocols. 2012; 5.

18. Gottesman MM. Mechanisms of cancer drug resistance. Annual review of medicine. 2002; 53: 615-627.
19. Czech MP, Aouadi M, Tesz GJ. RNAi-based therapeutic strategies for metabolic disease. Nat Rev Endocrinol. 2011; 7:473-484.

20. Jackson AL, Burchard J, Schelter J, Chau BN, Cleary M, Lim L, et al. Widespread siRNA "off-target" transcript silencing mediated by seed region sequence complementarity. RNA. 2006; 12: 1179-1187.

21. Summerton JE. Morpholino, siRNA, and S-DNA compared: impact of structure and mechanism of action on off-target effects and sequence specificity. Current topics in medicinal chemistry. 2007; 7: 651-660.

22. Banan M, Puri N. The ins and outs of RNAi in mammalian cells. Curr Pharm Biotechnol. 2004; 5: 441-450.

23. Gary DJ, Puri N, Won YY. Polymer-based siRNA delivery: perspectives on the fundamental and phenomenological distinctions from polymer-based DNA delivery. J Control Release. 2007; 121: 64-73.

24. Motta Mda G, Pedro EN, Coelho DF, Wachholz NI, Greff AP. [Trajectory of a research on the HIV/AIDS theme: limits and (im) possibilities]. Rev Gaucha Enferm. 2009; 30: 343-347.

25. Williams BR. Signal integration via PKR. Sci STKE. 2001; 2001: re2.

26. Sioud M. Single-stranded small interfering RNA are more immunostimulatory than their double-stranded counterparts: a central role for 2'-hydroxyl uridines in immune responses. Eur J Immunol. 2006; 36: 1222-1230.

27. Kodym R, Kodym E, Story MD. 2'-5'-Oligoadenylate synthetase is activated by a specific RNA sequence motif. Biochem Biophys Res Commun. 2009; 388: 317-322.

28. Leuschner PJ, Ameres SL, Kueng S, Martinez J. Cleavage of the siRNA passenger strand during RISC assembly in human cells. EMBO Rep. 2006; 7: 314-320.

29. Jang SH, Wientjes MG, Lu D, Au JL. Drug delivery and transport to solid tumors. Pharm Res. 2003; 20: 1337-1350.

30. Pecot CV, Calin GA, Coleman RL, Lopez-Berestein G, Sood AK. RNA interference in the clinic: challenges and future directions. Nat Rev Cancer. 2011; 11: 59-67.

31. Illum L, Davis SS. The organ uptake of intravenously administered colloidal particles can be altered using a non-ionic surfactant (Poloxamer 338). FEBS letters. 1984; 167: 79-82.

32. Norman ME, Williams P, Illum L. Influence of block copolymers on the adsorption of plasma proteins to microspheres. Biomaterials. 1993; 14: 193-202.

33. Rippe B, Rosengren BI, Carlsson O, Venturoli D. Transendothelial transport: the vesicle controversy. Journal of vascular research. 2002; 39: 375-390.

34. Juliano R, Bauman J, Kang H, Ming X. Biological barriers to therapy with antisense and siRNA oligonucleotides. Molecular pharmaceutics. 2009; 6: 686-695.

35. Akinc A, Querbes W, De S, Qin J, Frank-Kamenetsky M, Jayaprakash KN, et al. Targeted delivery of RNAi therapeutics with endogenous and exogenous ligand-based mechanisms. Mol Ther. 2010; 18: 1357-1364.

36. Kanasty R, Dorkin JR, Vegas A, Anderson D. Delivery materials for siRNA therapeutics. Nature materials. 2013; 12: 967-977.

37. Depristo MA, Banks E, Poplin R, Garimella KV, Maguire JR, Hartl C, et al. A framework for variation discovery and genotyping using next-generation DNA sequencing data. Nat Genet. 2011; 43: 491-498.

38. Dominska M, Dykxhoorn DM. Breaking down the barriers: siRNA delivery and endosome escape. J Cell Sci. 2010; 123: 1183-1189.

39. Jiang W, Kim BYS, Rutka JT, Chan WCW. Nanoparticle-mediated cellular response is size-dependent. Nature Nanotechnology. 2008; 3: 145-150.

40. McNeil SE. Nanoparticle therapeutics: a personal perspective. Wiley Interdisciplinary Reviews: Nanomedicine and Nanobiotechnology. 2009; 1: 264-271.

41. Sajja HK, East MP, Mao H, Wang YA, Nie S, Yang L. Development of Multifunctional Nanoparticles for Targeted Drug Delivery and Noninvasive Imaging of Therapeutic Effect. Current drug discovery technologies. 2009; 6: 43-51.

42. Whitehead KA, Langer R, Anderson DG. Knocking down barriers: advances in siRNA delivery. Nature Reviews Drug Discovery. 2009; 8: 129-138.

43. Gao W, Xiao Z, Radovic-Moreno A, Shi J, Langer R, Farokhzad OC. Progress in siRNA Delivery Using Multifunctional Nanoparticles. Methods in Molecular Biology. 2010; 629: 53-67.

44. Huang L, Sullenger B, Juliano R. The role of carrier size in the pharmacodynamics of antisense and siRNA oligonucleotides. Journal of Drug Targeting. 2010; 18: 567-574.

45. Liu G, Swierczewska M, Lee S, Chen X. Functional nanoparticles for molecular imaging guided gene delivery. Nano Today. 2010; 5: 524-539.

46. Stanton MG, Colletti SL. Medicinal Chemistry of siRNA Delivery. Journal of Medicinal Chemistry. 2010; 53: 7887-7901.

47. Soutschek J, Akinc A, Bramlage B, Charisse K, Constien R, Donoghue M, et al. Therapeutic silencing of an endogenous gene by systemic administration of modified siRNAs. Nature. 2004; 432: 173-178.

48. Wolfrum C, Shi S, Jayaprakash KN, Jayaraman M, Wang G, Pandey RK, et al. Mechanisms and optimization of in vivo delivery of lipophilic siRNAs. Nature Biotechnology. 2007; 25: 1149-1157.

49. Naito M, Ishii T, Matsumoto A, Miyata K, Miyahara Y, Kataoka K. A phenylboronate-functionalized polyion complex micelle for ATP-triggered release of siRNA. Angew Chem Int Ed Engl. 2012; 51: 10751-10755.

50. Lee SJ, Huh MS, Lee SY, Min S, Lee S, Koo H, et al. Tumor-Homing Poly-siRNA/Glycol Chitosan Self-Cross-Linked Nanoparticles for Systemic siRNA Delivery in Cancer Treatment. Angew Chem Int Edit. 2012; 51: 7203-7207.

51. Torchilin V. Tumor delivery of macromolecular drugs based on the EPR effect. Adv Drug Deliver Rev. 2011; 63: 131-135. 
52. Tasciotti E, Liu X, Bhavane R, Plant K, Leonard AD, Price BK, et al. Mesoporous silicon particles as a multistage delivery system for imaging and therapeutic applications. Nature Nanotechnology. 2008; 3: 151-157.

53. Serda RE, Godin B, Blanco E, Chiappini C, Ferrari M. Multi-stage delivery nano-particle systems for therapeutic applications. Biochimica et Biophysica Acta. 2011; 1810: 317-329.

54. Chen AM, Zhang M, Wei D, Stueber D, Taratula O, Minko T, et al. Co-delivery of Doxorubicin and Bcl-2 siRNA by Mesoporous Silica Nanoparticles Enhances the Efficacy of Chemotherapy in Multidrug-Resistant Cancer Cells. Small. 2009; 5: 2673-2677.

55. Xia TA, Kovochich M, Liong M, Meng H, Kabehie S, George S, et al. Polyethyleneimine Coating Enhances the Cellular Uptake of Mesoporous Silica Nanoparticles and Allows Safe Delivery of siRNA and DNA Constructs. ACS nano. 2009; 3: 3273-3286

56. Meng H, Liong M, Xia T, Li Z, Ji Z, Zink JI, et al. Engineered design of mesoporous silica nanoparticles to deliver doxorubicin and P-glycoprotein siRNA to overcome drug resistance in a cancer cell line. ACS nano. 2010; 4: 4539-4550.

57. Meng H, Mai WX, Zhang H, Xue M, Xia T, Lin S, et al. Codelivery of an optimal drug/siRNA combination using mesoporous silica nanoparticles to overcome drug resistance in breast cancer in vitro and in vivo. ACS nano. 2013; 7: 994-1005.

58. Meng H, Xue M, Xia T, Ji ZX, Tarn DY, Zink JI, et al. Use of Size and a Copolymer Design Feature To Improve the Biodistribution and the Enhanced Permeability and Retention Effect of Doxorubicin-Loaded Mesoporous Silica Nanoparticles in a Murine Xenograft Tumor Model. ACS nano. 2011; 5: 4131-4144.

59. Cauda V, Schlossbauer A, Bein T. Bio-degradation study of colloidal mesoporous silica nanoparticles: Effect of surface functionalization with organo-silanes and poly(ethylene glycol). Micropor Mesopor Mat. 2010; 132: 60-71.

60. Souris JS, Lee $\mathrm{CH}$, Cheng $\mathrm{SH}$, Chen $\mathrm{CT}$, Yang CS, Ho JAA, et al. Surface charge-mediated rapid hepatobiliary excretion of mesoporous silica nanoparticles. Biomaterials. 2010; 31: 5564-5574.

61. Chen YC, Bathula SR, Li J, Huang L. Multifunctional Nanoparticles Delivering Small Interfering RNA and Doxorubicin Overcome Drug Resistance in Cancer. J Biol Chem. 2010; 285: 22639-22650.

62. Zhang HY, Dunphy DR, Jiang XM, Meng H, Sun BB, Tarn D, et al. Processing Pathway Dependence of Amorphous Silica Nanoparticle Toxicity: Colloidal vs Pyrolytic. J Am Chem Soc. 2012; 134: 15790-15804.

63. Rosenholm JM, Mamaeva V, Sahlgren C, Linden M. Nanoparticles in targeted cancer therapy: mesoporous silica nanoparticles entering preclinical development stage. Nanomedicine-Uk. 2012; 7: 111-120.

64. Park JW, Bae KH, Kim C, Park TG. Clustered Magnetite Nanocrystals Cross-Linked with PEI for Efficient siRNA Delivery. Biomacromolecules. 2011; 12: $457-465$

65. Boyer C, Priyanto P, Davis TP, Pissuwan D, Bulmus V, Kavallaris M, et al. Anti-fouling magnetic nanoparticles for siRNA delivery. J Mater Chem. 2010; 20: 255-265.

66. Mok H, Veiseh O, Fang C, Kievit FM, Wang FY, Park JO, et al. pH-Sensitive siRNA Nanovector for Targeted Gene Silencing and Cytotoxic Effect in Cancer Cells. Molecular pharmaceutics. 2010; 7: 1930-1939.

67. Lee JH, Lee $\mathrm{K}$, Moon SH, Lee $\mathrm{Y}$, Park TG, Cheon J. All-in-one target-cell-specific magnetic nanoparticles for simultaneous molecular imaging and siRNA delivery. Angew Chem Int Ed Engl. 2009; 48: 4174-4179.

68. Liu G, Xie J, Zhang F, Wang ZY, Luo $K$, Zhu $L$, et al. N-Alkyl-PEI-Functionalized Iron Oxide Nanoclusters for Efficient siRNA Delivery. Small. 2011; 7: 2742-2749.

69. Lim J, Clements MA, Dobson J. Delivery of short interfering ribonucleic acid-complexed magnetic nanoparticles in an oscillating field occurs via caveolae-mediated endocytosis. PloS one. 2012; 7: e51350.

70. Xing RJ, Liu G, Quan QM, Bhirde A, Zhang GF, Jin A, et al. Functional MnO nanoclusters for efficient siRNA delivery. Chem Commun. 2011; 47: 12152-12154.

71. Boussif O, Lezoualch F, Zanta MA, Mergny MD, Scherman D, Demeneix B, et al. A Versatile Vector for Gene and Oligonucleotide Transfer into Cells in Culture and in-Vivo - Polyethylenimine. Proceedings of the National Academy of Sciences of the United States of America. 1995; 92: 7297-7301.

72. Park JW, Mok H, Park TG. Epidermal growth factor (EGF) receptor targeted delivery of PEGylated adenovirus. Biochemical and Biophysical Research Communications. 2008; 366: 769-774.

73. Mok H, Park TG. Self-crosslinked and reducible fusogenic peptides for intracellular delivery of siRNA. Biopolymers. 2008; 89: 881-888.

74. Boisselier E, Astruc D. Gold nanoparticles in nanomedicine: preparations, imaging, diagnostics, therapies and toxicity. Chemical Society reviews. 2009; 38: $1759-1782$

75. Lee SH, Bae KH, Kim SH, Lee KR, Park TG. Amine-functionalized gold nanoparticles as non-cytotoxic and efficient intracellular siRNA delivery carriers. Int J Pharmaceut. 2008; 364: 94-101.

76. Giljohann DA, Seferos DS, Prigodich AE, Patel PC, Mirkin CA. Gene Regulation with Polyvalent siRNA-Nanoparticle Conjugates. J Am Chem Soc. 2009; 131: 2072-2073.

77. Elbakry A, Zaky A, Liebkl R, Rachel R, Goepferich A, Breunig M. Layer-by-Layer Assembled Gold Nanoparticles for siRNA Delivery. Nano Lett. 2009; 9: 2059-2064
78. Lytton-Jean AK, Langer R, Anderson DG. Five Years of siRNA Delivery: Spotlight on Gold Nanoparticles. Small. 2011; 7:1932-1937.

79. Kim ST, Chompoosor A, Yeh YC, Agasti SS, Solfiell DJ, Rotello VM. Dendronized Gold Nanoparticles for siRNA Delivery. Small. 2012; 8: 3253-3256.

80. Song WJ, Du JZ, Sun TM, Zhang PZ, Wang J. Gold Nanoparticles Capped with Polyethyleneimine for Enhanced siRNA Delivery. Small. 2010; 6: 239-246.

81. Reynolds JL, Law WC, Mahajan SD, Aalinkeel R, Nair B, Sykes DE, et al. Nanoparticle Based Galectin-1 Gene Silencing, Implications in Methamphetamine Regulation of HIV-1 Infection in Monocyte Derived Macrophages. J Neuroimmune Pharm. 2012; 7: 673-685.

82. Khlebtsov N, Dykman L. Biodistribution and toxicity of engineered gold nanoparticles: a review of in vitro and in vivo studies. Chemical Society reviews. 2011; 40: 1647-1671.

83. Schrand AM, Rahman MF, Hussain SM, Schlager JJ, Smith DA, Ali SF. Metal-based nanoparticles and their toxicity assessment. Wires Nanomed Nanobi. 2010; $2:$ 544-568.

84. Liu Z, Tabakman SM, Chen Z, Dai H. Preparation of carbon nanotube bioconjugates for biomedical applications. Nature Protocols. 2009; 4: 1372-1381.

85. Dresselhaus MS, Dresselhaus G, Avouris P. Carbon nanotubes : synthesis, structure, properties, and applications. Berlin: Springer; 2000.

86. Beguin F, Ehrburger P. Special issue on carbon nanotubes. Carbon. 2002; 40: 1619-1842.

87. Ajayan PM. Nanotubes from carbon. Chemical Reviews. 1999; 99: 1787-1799.

88. Ji ZF, Lin GF, Lu QH, Meng LJ, Shen XZ, Dong L, et al. Targeted therapy of SMMC-7721 liver cancer in vitro and in vivo with carbon nanotubes based drug delivery system. Journal of Colloid and Interface Science. 2012; 365: 143-149.

89. Pantarotto D, Briand JP, Prato M, Bianco A. Translocation of bioactive peptides across cell membranes by carbon nanotubes. Chem Commun. 2004; 1 : 16-17.

90. Pantarotto D, Singh R, McCarthy D, Erhardt M, Briand JP, Prato M, et al. Functionalized carbon nanotubes for plasmid DNA gene delivery. Angew Chem Int Edit. 2004; 43: 5242-5246.

91. Liu Z, Winters M, Holodniy M, Dai HJ. siRNA delivery into human T cells and primary cells with carbon-nanotube transporters. Angew Chem Int Edit. 2007; 46: 2023-2027

92. Zhang ZH, Yang XY, Zhang Y, Zeng B, Wang ZJ, Zhu TH, et al. Delivery of telomerase reverse transcriptase small interfering RNA in complex with positively charged single-walled carbon nanotubes suppresses tumor growth. Clinical Cancer Research. 2006; 12: 4933-4939.

93. Kam NWS, Liu Z, Dai HJ. Functionalization of carbon nanotubes via cleavable disulfide bonds for efficient intracellular delivery of siRNA and potent gene silencing. J Am Chem Soc. 2005; 127: 12492-12493.

94. Krajcik R, Jung A, Hirsch A, Neuhuber W, Zolk O. Functionalization of carbon nanotubes enables non-covalent binding and intracellular delivery of small interfering RNA for efficient knock-down of genes. Biochem Biophys Res Commun. 2008; 369: 595-602.

95. Wang X, Ren J, Qu X. Targeted RNA interference of cyclin A2 mediated by functionalized single-walled carbon nanotubes induces proliferation arrest and apoptosis in chronic myelogenous leukemia K562 cells. ChemMedChem. 2008; 3: 940-945.

96. Podesta JE, Al-Jamal KT, Herrero MA, Tian BW, Ali-Boucetta H, Hegde V, et al. Antitumor Activity and Prolonged Survival by Carbon-Nanotube-Mediated Therapeutic siRNA Silencing in a Human Lung Xenograft Model. Small. 2009; 5: 1176-1185.

97. Novoselov KS, Geim AK, Morozov SV, Jiang D, Zhang Y, Dubonos SV, et al. Electric field effect in atomically thin carbon films. Science. 2004; 306: 666-669.

98. Geim AK, Novoselov KS. The rise of graphene. Nature materials. 2007; 6 : 183-191.

99. Li XL, Wang XR, Zhang L, Lee SW, Dai HJ. Chemically derived, ultrasmooth graphene nanoribbon semiconductors. Science. 2008; 319: 1229-1232.

100. Li D, Müller MB, Gilje S, Kaner RB, Wallace GG. Processable aqueous dispersions of graphene nanosheets. Nature Nanotechnology. 2008; 3: 101-105.

101. Chen BA, Liu M, Zhang LM, Huang J, Yao JL, Zhang ZJ. Polyethylenimine-functionalized graphene oxide as an efficient gene delivery vector. J Mater Chem. 2011; 21: 7736-7741.

102. Feng LZ, Zhang SA, Liu ZA. Graphene based gene transfection. Nanoscale. 2011; 3: 1252-1257.

103. Hong BJ, Compton OC, An Z, Eryazici I, Nguyen ST. Successful Stabilization of Graphene Oxide in Electrolyte Solutions: Enhancement of Bio-functionalization and Cellular Uptake. ACS nano. 2012; 6: 63-73.

104. Kim H, Namgung $\mathrm{R}$, Singha K, Oh I-K, Kim WJ. Graphene Oxide-Polyethylenimine Nanoconstruct as a Gene Delivery Vector and Bioimaging Tool. Bioconjugate Chem. 2011; 22: 2558-2567.

105. Lu CH, Zhu CL, Li J, Liu JJ, Chen X, Yang HH. Using graphene to protect DNA from cleavage during cellular delivery. Chem Commun. 2010; 46: 3116-3118.

106. Zhang LM, Lu ZX, Zhao QH, Huang J, Shen H, Zhang ZJ. Enhanced Chemotherapy Efficacy by Sequential Delivery of siRNA and Anticancer Drugs Using PEI-Grafted Graphene Oxide. Small. 2011; 7: 460-464

107. Seabra AB, Paula AJ, de Lima R, Alves OL, Duran N. Nanotoxicity of Graphene and Graphene Oxide. Chem Res Toxicol. 2014; 27: 159-168.

108. Kolosnjaj J, Szwarc H, Moussa F. Toxicity studies of carbon nanotubes. Adv Exp Med Biol. 2007; 620: 181-204.

109. Biswas S, Torchilin V. Dendrimers for siRNA Delivery. Pharmaceuticals. 2013; 6: 161-183. 
110. Wu J, Huang W, He Z. Dendrimers as Carriers for siRNA Delivery and Gene Silencing: A Review. The Scientific World Journal. 2013; 2013: 1-16.

111. Menjoge AR, Kannan RM, Tomalia DA. Dendrimer-based drug and imaging conjugates: design considerations for nanomedical applications. Drug Discovery Today. 2010; 15: 171-185.

112. Patil ML, Zhang M, Betigeri S, Taratula O, He H, Minko T. Surface-Modified and Internally Cationic Polyamidoamine Dendrimers for Efficient siRNA Delivery. Bioconjugate Chem. 2008; 19: 1396-1403.

113. Patil ML, Zhang M, Minko T. Multifunctional Triblock Nanocarrier (PAMAM-PEG-PLL) for the Efficient Intracellular siRNA Delivery and Gene Silencing. ACS nano. 2011; 5: 1877-1887.

114. Patil ML, Zhang M, Taratula O, Garbuzenko OB, He H, Minko T. Internally Cationic Polyamidoamine PAMAM-OH Dendrimers for siRNA Delivery: Effect of the Degree of Quaternization and Cancer Targeting. Biomacromolecules. 2009; 10: 258-266.

115. Duncan R, Izzo L. Dendrimer biocompatibility and toxicity. Adv Drug Deliv Rev. 2005; 57: 2215-2237.

116. Oh YK, Park TG. siRNA delivery systems for cancer treatment. Adv Drug Deliv Rev. 2009; 61: 850-862.

117. Liu XQ, Sun CY, Yang XZ, Wang J. Polymeric-Micelle-Based Nanomedicine for siRNA Delivery. Part Part Syst Char. 2013; 30: 211-228.

118. Moschos SA, Williams AE, Lindsay MA. Cell-penetrating-peptide-mediated siRNA lung delivery. Biochemical Society transactions. 2007; 35: 807-810.

119. Cantini L, Attaway CC, Butler B, Andino LM, Sokolosky ML, Jakymiw A. Fusogenic-oligoarginine peptide-mediated delivery of siRNAs targeting the CIP2A oncogene into oral cancer cells. PloS one. 2013; 8: e73348.

120. Gabrielson NP, Lu H, Yin L, Kim KH, Cheng J. A cell-penetrating helical polymer for siRNA delivery to mammalian cells. Mol Ther. 2012; 20: 1599-1609.

121. Mo RH, Zaro JL, Shen WC. Comparison of cationic and amphipathic cell penetrating peptides for siRNA delivery and efficacy. Molecular pharmaceutics. 2012; 9: 299-309.

122. Vauthier C, Zandanel C, Ramon AL. Chitosan-based nanoparticles for in vivo delivery of interfering agents including siRNA. Current Opinion in Colloid \& Interface Science. 2013; 18: 406-418.

123. Han HD, Mangala LS, Lee JW, Shahzad MM, Kim HS, Shen D, et al. Targeted gene silencing using RGD-labeled chitosan nanoparticles. Clin Cancer Res. 2010; 16: 3910-3922.

124. Kim HS, Han HD, Armaiz-Pena GN, Stone RL, Nam EJ, Lee JW, et al. Functional roles of Src and Fgr in ovarian carcinoma. Clin Cancer Res. 2011; 17: 1713-1721.

125. Yang J, Li SP, Guo F, Zhang W, Wang YL, Pan Y. Induction of apoptosis by chitosan/HPV16 E7 SiRNA complexes in cervical cancer cells. Mol Med Rep. 2013; 7: 998-1002.

126. Saengkrit N, Sanitrum P, Woramongkolchai N, Saesoo S, Pimpha N, Chaleawlert-Umpon S, et al. The PEI-introduced CS shell/PMMA core nanoparticle for silencing the expression of E6/E7 oncogenes in human cervical cells. Carbohydrate polymers. 2012; 90: 1323-1329.

127. Steinbach JM, Weller CE, Booth CJ, Saltzman WM. Polymer nanoparticles encapsulating siRNA for treatment of HSV-2 genital infection. J Control Release. 2012; 162: 102-110.

128. Chen ML, Gao S, Dong MD, Song J, Yang CX, Howard KA, et al. Chitosan/siRNA Nanoparticles Encapsulated in PLGA Nanofibers for siRNA Delivery. ACS nano. 2012; 6: 4835-4844.

129. Zhou J, Patel TR, Fu M, Bertram JP, Saltzman WM. Octa-functional PLGA nanoparticles for targeted and efficient siRNA delivery to tumors. Biomaterials. 2012; 33: 583-591

130. Mu P, Nagahara S, Makita N, Tarumi Y, Kadomatsu K, Takei Y, Systemic delivery of siRNA specific to tumor mediated by atelocollagen: combined therapy using siRNA targeting $\mathrm{Bcl}-\mathrm{xL}$ and cisplatin against prostate cancer. International journal of cancer Journal international du cancer. 2009; 125: 2978-2990.

131. Minakuchi Y, Takeshita F, Kosaka N, Sasaki H, Yamamoto Y, Kouno M, et al. Atelocollagen-mediated synthetic small interfering RNA delivery for effective gene silencing in vitro and in vivo. Nucleic acids research. 2004; 32: e109.

132. Forootan SS, Bao ZZ, Forootan FS, Kamalian L, Zhang Y, Bee A, et al. Atelocollagen-delivered siRNA targeting the FABP5 gene as an experimental therapy for prostate cancer in mouse xenografts. International journal of oncology. 2010; 36: 69-76.

133. Takeshita F, Minakuchi Y, Nagahara S, Honma K, Sasaki H, Hirai K, et al. Efficient delivery of small interfering RNA to bone-metastatic tumors by using atelocollagen in vivo. Proceedings of the National Academy of Sciences of the United States of America. 2005; 102: 12177-12182.

134. Hunter AC. Molecular hurdles in polyfectin design and mechanistic background to polycation induced cytotoxicity. Adv Drug Deliv Rev. 2006; 58: 1523-1531.

135. Davis ME. Non-viral gene delivery systems. Curr Opin Biotechnol. 2002; 13: 128-131.

136. Meyer M, Philipp A, Oskuee R, Schmidt C, Wagner E. Breathing Life into Polycations: Functionalization with $\mathrm{pH}$-Responsive Endosomolytic Peptides and Polyethylene Glycol Enables siRNA Delivery. J Am Chem Soc. 2008; 130: 3272-3273.

137. Gary DJ, Puri N, Won Y-Y. Polymer-based siRNA delivery: Perspectives on the fundamental and phenomenological distinctions from polymer-based DNA delivery. J Control Release. 2007; 121: 64-73.
138. Gary, DJ, Lee, H, Sharma, R, Lee, JS, Kim, Y, Cui, ZY, Jia, D, Bowman, VD, Chipman, PR, Wan, L, et al. Influence of nano-carrier architecture on in vitro siRNA delivery performance and in vivo biodistribution: polyplexes vs micelleplexes. ACS nano. 2011; 5:3493-3505.

139. Mok H, Lee SH, Park JW, Park TG. Multimeric small interfering ribonucleic acid for highly efficient sequence-specific gene silencing. Nature materials. 2010; 9: 272-278.

140. Matsumoto S, Christie RJ, Nishiyama N, Miyata K, Ishii A, Oba M, et al. Environment-responsive block copolymer micelles with a disulfide cross-linked core for enhanced siRNA delivery. Biomacromolecules. 2009; 10: 119-127.

141. West KR, Otto S. Reversible covalent chemistry in drug delivery. Current drug discovery technologies. 2005; 2: 123-160.

142. Jere D, Arote R, Jiang HL, Kim YK, Cho MH, Cho CS. Bioreducible polymers for efficient gene and siRNA delivery. Biomedical materials. 2009; 4: 025020.

143. Chung HJ, Hong CA, Lee SH, Jo SD, Park TG. Reducible siRNA dimeric conjugates for efficient cellular uptake and gene silencing. Bioconjug Chem. 2011; 22: 299-306.

144. Lee SY, Huh MS, Lee S, Lee SJ, Chung H, Park JH, et al. Stability and cellular uptake of polymerized siRNA (poly-siRNA)/polyethylenimine (PEI) complexes for efficient gene silencing. J Control Release. 2010; 141: 339-346.

145. Kozielski KL, Tzeng SY, Hurtado De Mendoza BA, Green JJ. Bioreducible Cationic Polymer-Based Nanoparticles for Efficient and Environmentally Triggered Cytoplasmic siRNA Delivery to Primary Human Brain Cancer Cells. ACS nano. 2014; 8: 3232-3241.

146. Kim SH, Jeong JH, Kim TI, Kim SW, Bull DA. VEGF siRNA Delivery System Using Arginine-Grafted Bioreducible Poly(disulfide amine). Molecular pharmaceutics. 2009; 6: 718-726.

147. Yoon HY, Kim HR, Saravanakumar G, Heo R, Chae SY, Um W, et al. Bioreducible hyaluronic acid conjugates as siRNA carrier for tumor targeting. J Control Release. 2013; 172: 653-661.

148. Namgung R, Kim WJ. A highly entangled polymeric nanoconstruct assembled by siRNA and its reduction-triggered siRNA release for gene silencing. Small. 2012; 8: 3209-3219.

149. Florinas S, Kim J, Nam K, Janat-Amsbury MM, Kim SW. Ultrasound-assisted siRNA delivery via arginine-grafted bioreducible polymer and microbubbles targeting VEGF for ovarian cancer treatment. J Control Release. 2014; 183: 1-8.

150. Kurkov SV, Loftsson T. Cyclodextrins. Int J Pharm. 2013; 453: 167-180.

151. Jansook P, Kurkov SV, Loftsson T. Cyclodextrins as solubilizers: formation of complex aggregates. Journal of pharmaceutical sciences. 2010; 99: 719-729.

152. Davis ME. The First Targeted Delivery of siRNA in Humans via a Self-Assembling, Cyclodextrin Polymer-Based Nanoparticle: From Concept to Clinic. Molecular pharmaceutics. 2009; 6: 659-668

153. Davis ME, Zuckerman JE, Choi CH, Seligson D, Tolcher A, Alabi CA, et al. Evidence of RNAi in humans from systemically administered siRNA via targeted nanoparticles. Nature. 2010; 464: 1067-1070.

154. Heidel JD, Liu JY, Yen Y, Zhou B, Heale BS, Rossi JJ, et al. Potent siRNA inhibitors of ribonucleotide reductase subunit RRM2 reduce cell proliferation in vitro and in vivo. Clin Cancer Res. 2007; 13: 2207-2215.

155. Bartlett DW, Davis ME. Impact of tumor-specific targeting and dosing schedule on tumor growth inhibition after intravenous administration of siRNA-containing nanoparticles. Biotechnology and bioengineering. 2008; 99: 975-985

156. Brahmamdam P, Watanabe E, Unsinger J, Chang KC, Schierding W, Hoekzema AS, et al. Targeted delivery of siRNA to cell death proteins in sepsis. Shock. 2009; 32: 131-139.

157. Heidel JD, Yu Z, Liu JY, Rele SM, Liang Y, Zeidan RK, et al. Administration in non-human primates of escalating intravenous doses of targeted nanoparticles containing ribonucleotide reductase subunit M2 siRNA. Proceedings of the National Academy of Sciences of the United States of America. 2007; 104: 5715-5721.

158. Bartlett DW, Su H, Hildebrandt IJ, Weber WA, Davis ME. Impact of tumor-specific targeting on the biodistribution and efficacy of siRNA nanoparticles measured by multimodality in vivo imaging. Proceedings of the National Academy of Sciences of the United States of America. 2007; 104: 15549-15554

159. Tiwari G, Tiwari R, Rai AK. Cyclodextrins in delivery systems: Applications. Journal of pharmacy \& bioallied sciences. 2010; 2: 72-79.

160. Hatakeyama H, Akita H, Ito E, Hayashi Y, Oishi M, Nagasaki Y, et al. Systemic delivery of siRNA to tumors using a lipid nanoparticle containing a tumor-specific cleavable PEG-lipid. Biomaterials. 2011; 32: 4306-4316.

161. Schroeder A, Levins CG, Cortez C, Langer R, Anderson DG. Lipid-based nanotherapeutics for siRNA delivery. Journal of Internal Medicine. 2009; 267: 9-21.

162. Tseng Y-C, Mozumdar S, Huang L. Lipid-based systemic delivery of siRNA. Adv Drug Deliver Rev. 2009; 61: 721-731.

163. Allen TM, Cullis PR. Drug Delivery Systems: Entering the Mainstream. Science. 2004; 303: 1818-1822.

164. Noble CO, Guo Z, Hayes ME, Marks JD, Park JW, Benz CC, et al. Characterization of highly stable liposomal and immunoliposomal formulations of vincristine and vinblastine. Cancer Chemotherapy and Pharmacology. 2009; 64: 741-751.

165. Drummond DC, Noble CO, Guo Z, Hayes ME, Connolly-Ingram C, Gabriel BS, et al. Development of a highly stable and targetable nanoliposomal formulation of topotecan. J Control Release. 2010; 141: 13-21. 
166. Lin QY, Chen J, Zhang ZH, Zheng G. Lipid-based nanoparticles in the systemic delivery of siRNA. Nanomedicine-Uk. 2014; 9: 105-120.

167. Hayes ME, Drummond DC, Kirpotin DB, Zheng WW, Noble COI, Park JW, et al. Genospheres: Self-assembling Nucleic Acid-Lipid Nanoparticles Suitable for Targeted Gene Delivery. Gene Therapy. 2006; 13: 646-651.

168. Bhattacharya S, Bajaj A. Advances in gene delivery through molecular design of cationic lipids. Chem Commun. 2009; 31: 4632-4656.

169. Kirpotin DB, Noble CO, Hayes ME, Huang Z, Kornaga T, Zhou Y, et al. Building and characterizing antibody-targeted lipidic nanotherapeutics. Methods in enzymology. 2012; 502: 139-166.

170. Hatakeyama $\mathrm{H}$, Akita $\mathrm{H}$, Harashima $\mathrm{H}$. A multifunctional envelope type nano device (MEND) for gene delivery to tumours based on the EPR effect: A strategy for overcoming the PEG dilemma. Adv Drug Deliver Rev. 2010; 63: 152-160.

171. Peerada Yingyuad MM, Carla Prata, Christos Kontogiorgis, Maya Thanou and Andrew D Miller. Enzyme-triggered PEGylated siRNA-nanoparticles for controlled release of siRNA. J RNAi Gene Silencing. 2014; 10: 9.

172. Carmona S, Jorgensen MR, Kolli S, Crowther C, Salazar FH, Marion PL, et al. Controlling HBV replication in vivo by intravenous administration of triggered PEGylated siRNA-nanoparticles. Molecular pharmaceutics. 2009; 6: 706-717.

173. Wang XM, Yu B, Ren W, Mo XK, Zhou CG, He HY, et al. Enhanced hepatic delivery of siRNA and microRNA using oleic acid based lipid nanoparticle formulations. J Control Release. 2013; 172: 690-698.

174. Zhdanov RI, Podobed OV, Vlassov VV. Cationic lipid-DNA complexes-lipoplexes-for gene transfer and therapy. Bioelectrochemistry. 2002; 58: 53-64.

175. Lv H, Zhang S, Wang B, Cui S, Yan J. Toxicity of cationic lipids and cationic polymers in gene delivery. J Control Release. 2006; 114: 100-109.

176. Landen CN, Jr., Chavez-Reyes A, Bucana C, Schmandt R, Deavers MT, Lopez-Berestein G, et al. Therapeutic EphA2 Gene Targeting In vivo Using Neutral Liposomal Small Interfering RNA Delivery. Cancer Research. 2005; 69: 6910-6918.

177. Merritt WM, Lin YG, Spannuth WA, Fletcher MS, Kamat AA, Han LY, et al. Effect of Interleukin-8 Gene Silencing With Liposome-Encapsulated Small Interfering RNA on Ovarian Cancer Cell Growth. Journal of the National Cancer Institute. 2009; 100: 359-372.

178. Ma H, Dallas A, Ilves $\mathrm{H}$, Shorenstein J, MacLachlan I, Klumpp K, et al. Formulated minimal-length synthetic small hairpin RNAs are potent inhibitors of hepatitis C virus in mice with humanized livers. Gastroenterology. 2014; 146: 63-66.

179. Geisbert TW, Lee AC, Robbins M, Geisbert JB, Honko AN, Sood V, et al. Postexposure protection of non-human primates against a lethal Ebola virus challenge with RNA interference: a proof-of-concept study. Lancet. 2010; 375: 1896-1905.

180. Ursic-Bedoya R, Mire CE, Robbins M, Geisbert JB, Judge A, MacLachlan I, et al. Protection against lethal Marburg virus infection mediated by lipid encapsulated small interfering RNA. The Journal of infectious diseases. 2014; 209: 562-570.

181. Peppas NA, Bures P, Leobandung W, Ichikawa H. Hydrogels in pharmaceutical formulations. European Journal of Pharmaceutics and Biopharmaceutics. 2000; 50: 27-46.

182. Raemdonck K, Van Thienen TG, Vandenbroucke RE, Sanders NN, Demeester J, De Smedt SC. Dextran microgels for time-controlled delivery of siRNA. Advanced Functional Materials. 2008; 18: 993-1001.

183. Blackburn WH, Dickerson EB, Smith MH, McDonald JF, Lyon LA. Peptide-Functionalized Nanogels for Targeted siRNA Delivery. Bioconjugate Chem. 2009; 20: 960-968.

184. Dickerson EB, Blackburn WH, Smith MH, Kapa LB, Lyon LA, McDonald JF. Chemosensitization of cancer cells by siRNA using targeted nanogel delivery. Bmc Cancer. 2010; 10: 10 .

185. Peppas NA, Hilt JZ, Khademhosseini A, Langer R. Hydrogels in biology and medicine: From molecular principles to bionanotechnology. Advanced Materials. 2006; 18: 1345-1360.

186. Coviello T, Matricardi P, Marianecci C, Alhaique F. Polysaccharide hydrogels for modified release formulations. J Control Release. 2007; 119: 5-24.

187. Lin CC, Metters AT. Hydrogels in controlled release formulations: Network design and mathematical modeling. Adv Drug Deliver Rev. 2006; 58: 1379-1408.

188. Ramakrishnan S. Hydrogel-siRNA for cancer therapy. Cancer Biology \& Therapy. 2011; 11: 849-851.

189. Krebs MD, Jeon O, Alsberg E. Localized and Sustained Delivery of Silencing RNA from Macroscopic Biopolymer Hydrogels. J Am Chem Soc. 2009; 131: 9204-9206.

190. Singh A, Suri S, Roy K. In-situ crosslinking hydrogels for combinatorial delivery of chemokines and siRNA-DNA carrying microparticles to dendritic cells. Biomaterials. 2009; 30: 5187-5200.

191. Han HD, Mora EM, Roh JW, Nishimura M, Lee SJ, Stone RL, et al. Chitosan hydrogel for localized gene silencing. Cancer Biology \& Therapy. 2011; 11: 839-845.

192. Lee H, Mok H, Lee S, Oh YK, Park TG. Target-specific intracellular delivery of siRNA using degradable hyaluronic acid nanogels. J Control Release. 2007; 119: 245-252.

193. Takahashi H, Wang YW, Grainger DW. Device-based local delivery of siRNA against mammalian target of rapamycin (mTOR) in a murine subcutaneous implant model to inhibit fibrous encapsulation. J Control Release. 2010; 147: 400-407

194. Kim C, Lee Y, Lee SH, Kim JS, Jeong JH, Park TG. Self-Crosslinked Polyethylenimine Nanogels for Enhanced Intracellular Delivery of siRNA. Macromolecular Research. 2011; 19: 166-171.

195. Lee SH, Choi SH, Kim SH, Park TG. Thermally sensitive cationic polymer nanocapsules for specific cytosolic delivery and efficient gene silencing of siRNA: Swelling induced physical disruption of endosome by cold shock. J Control Release. 2008; 125: 25-32.

196. Krebs MD, Jeon O, Alsberg E. Localized and Sustained Delivery of Silencing RNA from Macroscopic Biopolymer Hydrogels. J Am Chem Soc. 2009; 131: 9204-9206.

197. Laurent T. The Biology of Hyaluronan - Introduction. Ciba Foundation Symposia. 1989; 143: 1-5.

198. Hong CA, Lee SH, Kim JS, Park JW, Bae KH, Mok H, et al. Gene Silencing by siRNA Microhydrogels via Polymeric Nanoscale Condensation. J Am Chem Soc. 2011; 133: 13914-13917.

199. Derfus AM, Chen AA, Min D-H, Ruoslahti E, Bhatia SN. Targeted Quantum Dot Conjugates for siRNA Delivery. Bioconjugate Chem. 2007; 18: 1391-1396.

200. Alivisatos AP. Semiconductor clusters, nanocrystals, and quantum dots. Science. 1996; 271: 933-937.

201. Clapp AR, Medintz IL, Mauro JM, Fisher BR, Bawendi MG, Mattoussi H. Fluorescence resonance energy transfer between quantum dot donors and dye-labeled protein acceptors. J Am Chem Soc. 2004; 126: 301-310.

202. Gao XH, Cui YY, Levenson RM, Chung LWK, Nie SM. In vivo cancer targeting and imaging with semiconductor quantum dots. Nat Biotechnol. 2004; 22: 969-976.

203. Qi L, Gao X. Quantum dot-amphipol nanocomplex for intracellular delivery and real-time imaging of siRNA. Acs Nano. 2008; 2: 1403-1410.

204. Yezhelyev MV, Qi LF, O'Regan RM, Nie S, Gao XH. Proton-sponge coated quantum dots for siRNA delivery and intracellular imaging. J Am Chem Soc. 2008; 130: 9006-9012.

205. Lee H, Kim IK, Park TG. Intracellular trafficking and unpacking of siR$\mathrm{NA}$ /quantum dot-PEI complexes modified with and without cell penetrating peptide: confocal and flow cytometric FRET analysis. Bioconjug Chem. 2010; 21: $289-295$.

206. Derfus AM, Chen AA, Min DH, Ruoslahti E, Bhatia SN. Targeted quantum dot conjugates for siRNA delivery. Bioconjug Chem. 2007; 18: 1391-1396.

207. Probst CE, Zrazhevskiy P, Bagalkot V, Gao XH. Quantum dots as a platform for nanoparticle drug delivery vehicle design. Adv Drug Deliver Rev. 2013; 65: 703-718

208. Hardman R. A toxicologic review of quantum dots: toxicity depends on physicochemical and environmental factors. Environmental health perspectives. 2006; 114: 165-172.

209. Varkouhi AK, Foillard S, Lammers T, Schiffelers RM, Doris E, Hennink WE, et al. SiRNA delivery with functionalized carbon nanotubes. Int J Pharmaceut. 2011; 416: 419-425. 